OPEN ACCESS

Edited by:

Valentina Pucino,

University of Birmingham,

United Kingdom

Reviewed by:

Shun-Fen Tzeng,

National Cheng Kung University,

Taiwan

Michihito Kono,

Hokkaido University, Japan

*Correspondence:

Luca Peruzzotti-Jametti Ip429@cam.ac.uk Stefano Pluchino spp24@cam.ac.uk

Specialty section: This article was submitted to Autoimmune and

Autoinflammatory Disorders,

a section of the journal

Frontiers in Immunology

Received: 06 May 2021

Accepted: 31 May 2021

Published: 23 June 2021

Citation:

Peruzzotti-Jametti L, Willis CM,

Hamel R, Krzak G and Pluchino S

(2021) Metabolic Control of

Smoldering Neuroinflammation.

Front. Immunol. 12:705920.

doi: 10.3389/fimmu.2021.705920

\section{Metabolic Control of Smoldering Neuroinflammation}

\author{
Luca Peruzzotti-Jametti ${ }^{*}$, Cory M. Willis, Regan Hamel, Grzegorz Krzak \\ and Stefano Pluchino*
}

Department of Clinical Neurosciences and National Institute for Health Research (NIHR) Biomedical Research Centre, University of Cambridge, Cambridge, United Kingdom

Compelling evidence exists that patients with chronic neurological conditions, which includes progressive multiple sclerosis, display pathological changes in neural metabolism and mitochondrial function. However, it is unknown if a similar degree of metabolic dysfunction occurs also in non-neural cells in the central nervous system. Specifically, it remains to be clarified (i) the full extent of metabolic changes in tissue-resident microglia and infiltrating macrophages after prolonged neuroinflammation (e.g., at the level of chronic active lesions), and (ii) whether these alterations underlie a unique pathogenic phenotype that is amenable for therapeutic targeting. Herein, we discuss how cell metabolism and mitochondrial function govern the function of chronic active microglia and macrophages brain infiltrates and identify new metabolic targets for therapeutic approaches aimed at reducing smoldering neuroinflammation.

Keywords: microglia, macrophages, metabolism, immunometabolism, mitochondria, smoldering inflammation, progressive multiple sclerosis

\section{INTRODUCTION}

Cellular metabolism is at the foundation of all biological activities (1). While the metabolic processes that support cellular bioenergetics and survival have been extensively studied $(2,3)$, the role of metabolism in guiding complex cellular functions is yet to be completely understood. Extensive metabolic rewiring occurs in cells to adapt to the local microenvironment in physiological conditions (4), during development (5), and in conditions of disease (6), as cells try to preserve their functions under the shifting availability of energetic substrates.

In this review, we discuss how the regulation of nutrient uptake and consumption is regulated in myeloid cells, when instructed by physiological cues, and as they undergo polarisation in the context of neuroinflammation. Specifically, we highlight how the regulation of their metabolism changes homeostatic cell activities to guide cell activation and signalling in the persistently inflamed central nervous system (CNS).

\section{SMOLDERING NEUROINFLAMMATION IN PROGRESSIVE MS}

Multiple sclerosis (MS) is a chronic inflammatory condition of the CNS that is characterized by demyelination with axonal and neuronal degeneration (7). Most MS patients ( 85\%) present a relapsing-remitting course (RR), while the remaining $\sim 15 \%$ show a primary progressive (PP) disease 
course characterised by continuous neurological deterioration without definable relapses (8). As the disease evolves, the majority of RR MS patients also advance to a secondary progressive (SP) disease course, usually after 15-20 years from disease onset (9). Despite great successes in the development of therapies for RR MS and disease-modifying therapies that delay the conversion to SP MS (10), progressive MS patients still have limited treatment options $(9,11,12)$. Unfortunately, effective treatment of progressive MS remains elusive due to the occurrence of specific degenerative mechanisms that characterize progressive MS, which are distinct from RR MS and are not sufficiently targeted by the approved immunomodulatory compounds (9).

In RR MS, active plaques predominate, and lesions show a diffuse perivascular and parenchymal $\mathrm{T}$ cell infiltration that is the substrate of clinical attacks (13). However, as the disease evolves, there is a shift from a $\mathrm{T}$ cell mediated adaptive immune response towards an innate immune activation $(13,14)$. In fact, progressive MS, like many other neurodegenerative CNS diseases [such as Alzheimer's disease (AD), Parkinson's disease (PD), and Huntington's disease], is characterized by a persistent state of CNS inflammation that is driven by myeloid cell activation $(8,15-18)$.

In progressive MS, myeloid cells are present in the normal appearing white matter (NAWM), in subpial cortical lesions, and, most importantly, in smoldering plaques $(13,19)$. Smoldering plaques are histopathologically defined as slowly expanding lesions that are characterized by a rim of activated myeloid cells and a slow expansion of the pre-existing plaque edge $(19,20)$. Here, increased activation of myeloid cells correlates with demyelination and axonal loss, leading to higher clinical disability in patients with progressive MS $(8,14$, 18). Indeed, current magnetic resonance imaging (MRI) tools aimed at assessing chronic active and smoldering lesions have emerged as a diagnostic tool to predict secondary disease progression $(21,22)$, as well as clinical progression in PP MS patients (23).

These data suggest that a slowly expanding, myeloidmediated, smoldering neuroinflammation is the core feature from which progression starts and evolves in MS. Therefore, understanding the mechanisms underpinning chronic myeloid cell activation in the CNS may hold the promise of identifying new targets to treat and/or delay disease progression (24).

\section{MYELOID CELLS DYNAMICS IN NEUROINFLAMMATION}

Far from being a homogenous cell population, the cellular makeup of CNS myeloid cells is instead spatially and temporally heterogenous, being under tight regulation by (patho)physiological cues that determine beneficial and/or detrimental immune cell activation (25). Recent single cell technologies have unveiled how the immune landscape of the brain drastically changes with fluctuations in the neuroinflammatory status (26).

In the healthy CNS, immune function is exclusively attributed to parenchymal and extra-parenchymal myeloid cells. Within the brain parenchyma, the most immune-privileged compartment of the CNS, the only resident myeloid cells are microglia (27). Microglia are specialized macrophages that are seeded into the brain from the extra-embryonic yolk sac during embryogenesis (28), and they have key roles in synaptic pruning, phagocytosis, and immune surveillance (29). During early CNS development, microglia are distinguished by several unique transcriptional markers (Arg1, Rrm2, Ube2c, Cenpa, Fabp5, Spp1, Hmox 1, and Ms4a7) associated with cell cycle, phagocytosis, lipid metabolism, and surveillance, which highlights the ongoing maturation of these cells (30). Microglia exhibit dynamic heterogeneity that fluctuates throughout the life of the mouse with the highest diversity occurring in the developmental stage, followed by a decline during adulthood, and increased heterogeneity during CNS diseases (30). In fact, during CNS maturation, healthy adult parenchymal microglia lose their developmental heterogeneity and begin to express "homeostatic" markers (P2ry12, Fcrls, C1qa, Selplg, and Tmem119) related to lipid metabolism and immune cell interaction (30-32). Interestingly, this transition is seemingly regulated by Maf bZIP transcription factor B (MAFB), which controls myeloid cell differentiation and cellular responses to viral infection (31).

Within the CNS borders, such as the dural meninges, the cellular make-up is mostly dominated by $\mathrm{T}$ and $\mathrm{B}$ cells with a minority of cells constituting macrophages and monocytes. This diverse and complex immune surveillance network facilitates the interaction between lymphocytes and macrophages at specialized immune hubs located along the dural sinuses (33). Borderassociated macrophages (BAMs) [also known as CNSassociated macrophages] localized in the leptomeninges, perivascular space, and choroid plexus, are responsible for immune surveillance, together with a small proportion of other immune cells, such as dendritic cells (DCs) and neutrophils (34). BAMs share similar transcriptional markers with microglia [Aif1 (encoding Iba1), Csf1r, and Cx3crl] $(30,35)$ and some transcriptional signatures of developing microglia overlap with BAM clusters ( $M s 4 a 7, C c r 1$, and $M r c 1$ ), possibly suggesting ongoing maturation status (30).

In the context of neuroinflammation, the brain immune landscape drastically changes. In mice affected by experimental autoimmune encephalomyelitis (EAE), an animal model of MS, the CNS is predominantly populated by short-lived infiltrating cells (Ly6 $\mathrm{C}^{\text {hi }}$ and Ly6 $\mathrm{C}^{\text {lo }}$ monocyte-derived cells [MdCs]) and $\mathrm{T}$ cells that infiltrate during the acute phase of disease through a "leaky" blood-brain barrier (BBB) (34). Here, BAM cell numbers decrease and their phenotype becomes more homogenous, with nearly all BAMs exclusively expressing MHCII and CD38 (34). At the peak of disease, microglia downregulate homeostatic markers and shift their phenotype towards a pro-inflammatory state whereby they overexpress IFN- $\gamma$-responsive genes [H2 
(encoding MHCII) and Scal], which imply increased microglia$\mathrm{T}$ cell interactions. Exclusively to the peak phase of EAE, four sub-populations of disease associated microglia (DAM) emerge (daMG1-4), which are distinguished by their unique expression patterns of chemokines, cytokines, and cysteine proteases (36). Although all four populations are specific to EAE, only three are identified within demyelinating lesions (daMG2-4) and exhibit similar downregulation of homeostatic genes $\left(P 2 r y 12^{\text {lo }}\right.$, Tmem119 $\left.9^{\mathrm{lo}}, M d 1^{\mathrm{hi}}\right)$. DaMG2 upregulates Cd74, Ctsb, and Apoe but proliferate less compared to the daMG3, whereas daMG3 expresses high levels of Cxcl10, Tnf, and Ccl4. Finally, daMG4 overexpress Ccl5, Ctss, and Itm2b (36). Further studies investigating myeloid cells in chronic EAE are required to understand whether these daMG profiles are transient. Nonetheless, similar findings are observed in the brain of patients with MS, where specific DAMs downregulate the expression of homeostatic genes (TMEM119, P2RY12, and $S L C 2 A 5)$ and upregulate $A P O E$ and $M A F B$ in late-active demyelinating lesions (37). These clusters were highly enriched in CTSD, APOC1, GPNMB, CD74, HLA-DRA, and HLA-DRB, which further supports the notion of increased microglial heterogeneity during CNS insult not only in EAE but also in the MS brain (38). Of note, analogous DAM transcriptional changes are also confirmed in the $5 x F A D$ animal model of $\mathrm{AD}$, cuprizone-mediated demyelination, and facial nerve axotomy where downregulation of canonical microglial genes (P2ry12/13, Cx3cr1, Tmem119) is coupled with the upregulation of genes related to phagocytosis and lipid metabolism (Apoe, Lpl, Cst7, Ctsd, Tyrobp, and Trem2) (26).

Understanding how these unique, disease-specific, microglial phenotypes can be targeted to promote a beneficial phenotype that ultimately ameliorates smoldering CNS inflammation is a current research challenge that will certainly uncover new therapeutic avenues.

\section{GLUCOSE AND GLUTAMINE METABOLISM}

Strong evidence has revealed that changes in the reactive states of macrophages and microglia can be regulated by their cellular metabolism (24). How the unique metabolic environment of the brain regulates the effector function of myeloid cells in health and disease is only now starting to be uncovered.

The CNS has intrinsic high metabolic demands associated with neural activity, as $\sim 20 \%$ of the body's glucose and oxygen is used by the CNS, despite only accounting for $2 \%$ of the total body weight (39). Glucose is shuttled from the blood via specialized glucose transporters (GLUTs) to provide fuel for cellular functions (40). Despite the high utilization of glucose by the CNS, only a small pool of nutrient reserves is stored as glycogen $(41,42)$. Therefore, tight regulation of glucose metabolism is critical for brain physiology, as disturbed glucose metabolism may contribute to several neurodegenerative diseases $(43,44)$.
Microglia require a large amount of energy to perform homeostatic functions. This is accomplished by microglia preferentially utilizing glucose as the main source of metabolic fuel, which is transported into microglia primarily by GLUT1, 3, and $5(45,46)$ to support oxidative metabolism. In oxidative metabolism, glucose is broken down into pyruvate through glycolysis, which is shuttled into the mitochondria where it is utilized by the tricarboxylic acid cycle (TCA) to drive oxidative phosphorylation (OXPHOS); ultimately producing adenosine triphosphate (ATP) (47) (Figure 1). Oxidative metabolism is the primary source for energy of microglia under homeostasis, as shown by transcriptomic analysis of ex vivo isolated mouse brain microglia, which express the full complement of genes required for both glycolytic and oxidative energy metabolism $(48,49)$. The ability of microglia to utilize glucose as a primary substrate for energy production has been mainly investigated in vitro. Primary rat microglia and the BV2 microglial cell line cultured in the presence of 2-deoxyglucose (2DG), which inhibits hexokinase 2 (HK2) and blocks glycolysis, leads to ATP depletion and cell death (50), indicating a reliance of microglia on glucose utilization for normal functioning. During experimental glucose starvation, primary microglia isolated from CD-1 IGS mice and the BV2 microglial cell line are able to maintain oxidative metabolism using other available substrates (glutamine, lactate, pyruvate, ketone bodies) (51). The reliance of microglia on oxidative metabolism through glucose has been recently confirmed in vivo in mice. Using endogenous fluorescence lifetime imaging (FLIM) of intracellular nicotinamide adenine dinucleotide phosphate (NADPH), as well as time-lapse two-photon imaging, microglia have been observed to maintain a glycolytic profile under resting conditions (52). Further, in conditions of aglycemia, microglia switches from glycolysis to glutaminolysis of extracellular glutamine, a major substrate for the generation of both excitatory and inhibitory neurotransmitters (53), in a mechanistic target of rapamycin (mTOR)-dependent manner to maintain OXPHOS and their immune surveillance functions (52). This suggests that microglia display bioenergetic versatility and, like peripheral macrophages, possess the ability to adapt its metabolic pathways to use substrates available in the local environment (51).

The ability of macrophages to shift or reprogram their metabolism to changes in the microenvironment is a key feature that underlies the complex, long-term changes of these cells under inflammatory conditions. In fact, immune cell polarization after inflammatory activation leads to drastic reprogramming of cellular metabolism pathways. A key finding is that macrophages exposed to an inflammatory stimulus shift their metabolism from oxidative metabolism to aerobic glycolysis (54), with a concomitant increase in the enzymatic activity of enzymes involved in glucose metabolism (55) and several transcription factors, including hypoxia-inducible factor-1 alpha $(\mathrm{HIF} 1 \alpha)$ and mTOR (56) (Figure 1). This metabolic switch occurs when macrophages are first faced with an immune challenge to support and enable the rapid production of ATP (57) - regardless of the availability of oxygen - which is 


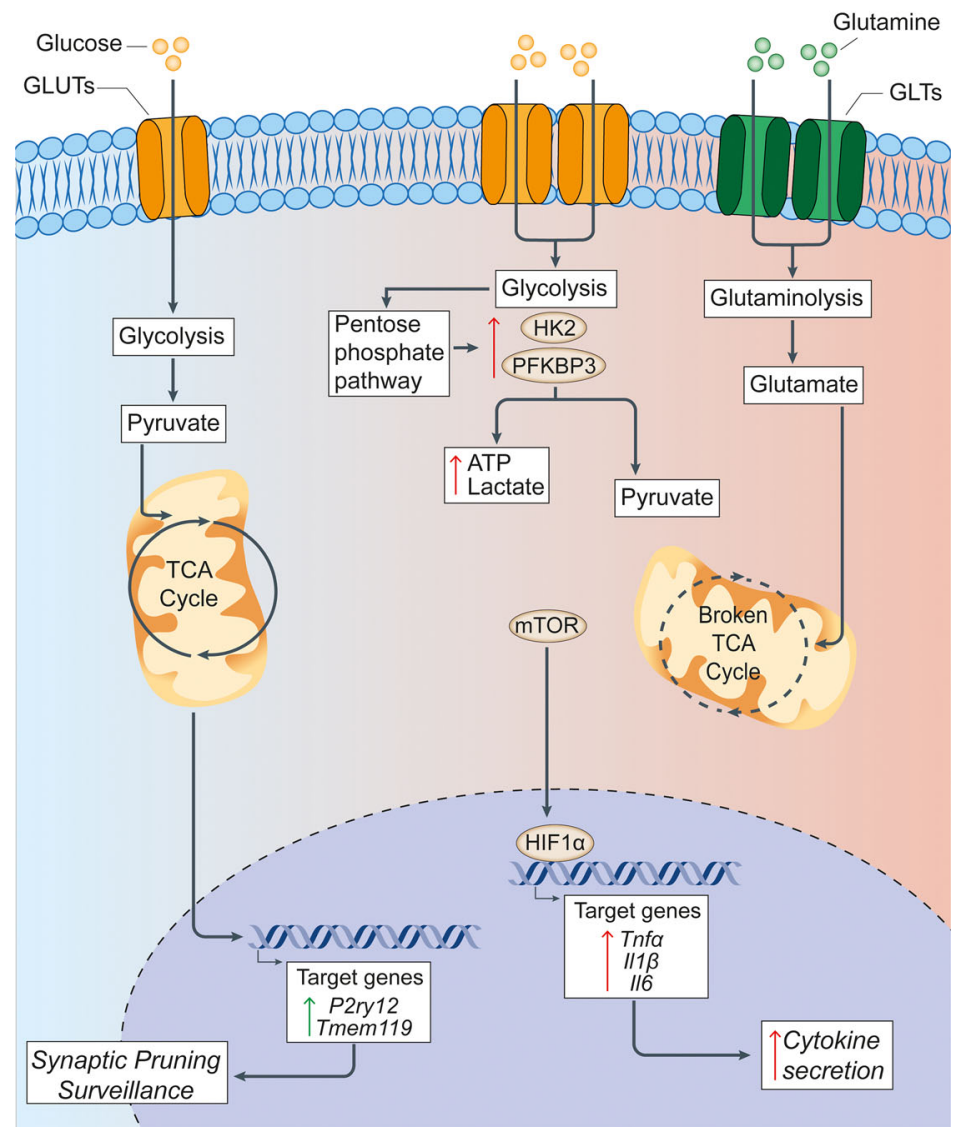

FIGURE 1 | Glucose metabolism in microglia under homeostatic and inflammatory conditions. Under homeostatic conditions, extracellular glucose is transported into microglial cells through specialized glucose transporters, where it is converted into pyruvate through cytoplasmic glycolysis. Pyruvate is then actively transported across the mitochondrial membrane to drive the TCA cycle. The energy and metabolites produced in the TCA cycle can then support the expression of the homeostatic microglial genes P2ry12 and Tmem119, which facilitate microglial functions of synaptic pruning and immune surveillance. In pro-inflammatory conditions, microglia have a broken TCA cycle and increase the expression of membrane transporters to facilitate the uptake of glucose and glutamine, thus driving enhanced glycolysis and glutaminolysis. Glycolysis is supported by increased expression of the rate-limiting enzymes of glycolysis HK2 and PFKBP3. This leads to the increased generation of lactate and ATP to compensate for the broken TCA cycle, and shunting of metabolites into the pentose phosphate pathway. The increased glycolysis is sustained by the activation of nuclear transcription factors HIF1 $\alpha$ and mTOR that support the synthesis and production of cytokines for secretion. Green arrows = homeostatic effects. Red arrows = pro-inflammatory effects. GLUT, glucose transporter; TCA, tricarboxylic acid cycle; GLT, glutamate transporter; HK2, hexokinase 2; PFKBP3, 6-phosphofructo-2-kinase/fructose-2,6-biphosphate-3; HIF1 $\alpha$, hypoxia inducible factor $1 \alpha$; ATP, adenosine triphosphate; mTOR, mechanistic target of rapamycin; TNF $\alpha$, tumor necrosis factor alpha; $\| 1 \beta$, interleukin-1 $\beta$; $\| 6$, interleukin-6.

similar to the Warburg effect described in cancer cells (58). Here, the increased consumption of glucose by activated macrophages leads to the generation of downstream products, such as glucose6-phosphate and pyruvate, which feed into the pentose phosphate pathway (PPP) and TCA cycle, respectively. The PPP facilitates the synthesis of proteins, nucleotides, and reactive oxygen species (ROS) to support cellular function during immune challenge (59).

Despite the extensive study of metabolic reprogramming in macrophages during inflammation, very little emphasis has yet been placed on assessing metabolism in microglia under neuroinflammatory conditions. Early studies investigating the links between metabolism and microglial activation identified metabolic modifications similar to those observed in peripherally activated macrophages, such as a shift from oxidative metabolism towards a more glycolytic profile after exposure to pro-inflammatory stimuli such as the toll-like receptor (TLR) ligand lipopolysaccharide (LPS). BV2 microglia treated with LPS exhibit increased lactate production and decreased mitochondrial ATP production, which is indicative of a shift to glycolysis (60). Another study confirmed the increased glucose consumption and glycolytic enzyme activity in parallel with increased anaerobic glycolysis and PPP utilization following LPS and IFN- $\gamma$ treatment (61). Mouse primary microglia 
treated with IFN- $\gamma$ result in a metabolic switch towards glycolysis and the retention of iron nanoparticles that is thought to be driven by 6-phosphofructo-2-kinase/fructose-2,6-biphosphate (PFKFB)3, an enzyme involved in glycolysis (62). The treatment of primary microglia with LPS for 24 hours also causes a shift from OXPHOS to glycolysis (63), which is mediated through the activation of the mTOR pathway and leads to enhanced ROS production (64). The metabolic switch is abolished following the addition of the phosphatidylinositol 3'kinase antagonist LY294002, rapamycin or torin1, which all suppress the phosphorylation of mTOR (64). Further, 2DG treatment of primary mouse microglia in parallel with LPS stimulation inhibits glycolysis with subsequent downregulation of LPS-induced genes (Il6, Ill $\beta$, and Nos2) and cytokine production (IL-6 and IL-1 $\beta$ ) (65). Recently, primary mouse microglia treated with IL- $1 \beta$ and IFN- $\gamma$ for 24 hours not only exhibit increased glucose metabolism but also glutamine metabolism through glutaminolysis. Interestingly, within this same study, human microglia-like cells differentiated from pluripotent stem cells treated with LPS for 24 hours exhibit increased $P F K B 3$ gene expression and increased glycolysis. The use of two-photon FLIM imaging to interrogate the metabolic signatures of individual microglia in acutely prepared mouse hippocampal slices exposed to LPS revealed an increase in aerobic glycolysis in microglia that is blocked by the addition of 2DG (5 mM) (66).

BV2 microglia, and the B6M7 microglial cell line, treated with LPS and IFN- $\gamma$ exhibit the expected metabolic shift towards enhanced glycolysis and increased gene expression of GLUT1. The inhibition of GLUT1 with STF31 in pro-inflammatory conditions specifically prevents the increase in microglial glucose uptake and attenuates the upregulation of inflammatory cytokines TNF- $\alpha$, IL-1 $\beta$, IL-6, and CCL2 in vitro, whereas an intraperitoneal injection of STF31 in a mouse model of light-induced retinal degeneration leads to reduced microglia activation and retinal degeneration in vivo (46). In BV2 and primary mouse microglia cultured in a hypoxic environment ( $1 \%$ oxygen), HK2, the first rate-limiting enzyme in glycolysis, is increased and correlates with enhanced glycolysis (67). Here, the pharmacological inhibition of HK2 with lonidamine impairs the activation profiles of both BV2 and primary microglia under hypoxia. HK2 blockade prevents ischemic brain injury by repressing microglia mediated neuroinflammation in a rat experimental model of stroke in vivo (67).

These studies suggest that under inflammatory conditions, microglia exhibit an increased glycolysis to OXPHOS ratio, similarly to what occurs in peripherally activated macrophages and during the Warburg effect of cancer cells. In summary, these studies strongly indicate that microglial polarization results in significant changes in the preferred metabolic pathway, from oxidative metabolism in homeostasis to a reliance on glycolysis and glutaminolysis in pro-inflammatory states.

Therefore, focusing on small molecules and/or drugs that promote oxidative metabolism over glycolysis will have profound impacts in the way we approach neuroinflammatory and neurodegenerative conditions.

\section{LIPID SENSING AND SIGNALLING IN MYELOID CELLS}

Lipids are fundamental building blocks of cell membranes and myelin in the brain (68-70). In the context of CNS damage, including demyelinating diseases, lipids play a key role in modulating inflammatory responses and contribute to metabolic dysfunction, which is an important aspect of disease pathophysiology $(71,72)$. In particular, the metabolism of lipids is central to both homeostasis and inflammatory responses in CNS myeloid cells, where it plays vital roles in respiration, activation, inflammatory signalling, migration, and phagocytosis $(70,73)$. Indeed, recent transcriptomics studies have provided indirect evidence supporting drastic changes in the lipid metabolism of activated microglia, as seen by the upregulation of lipid metabolism genes such as Trem2, Apoe, Spp1, Cts7, Lpl, and Fabp5 under inflammatory conditions (30, $70,74,75)$. However, the role of these genes and pathways is still under investigation, especially in diseases where myelin deposition in the CNS parenchyma can exceed the lipid processing capacity of myeloid cells (Figure 2) (73, 76, 77).

The basis of the myeloid cell response to lipids is determined by the carefully regulated composition of phospholipids (PLs) in the cell membrane. PLs are formed from two fatty acids (FAs), a phosphate group, and a glycerol or sphingosine molecule. While they are best known as major components of the cell membrane, PLs are also critical for vesicle formation, apoptosis, and as metabolic intermediates for the production of both pro- and anti-inflammatory molecules (70). Sphingosine containing PLs, also known as sphingolipids, are prominent signalling molecules in the CNS. Sphingosine-1phosphate (S1P), derived from the phosphorylation of sphingosine, can act as an intracellular intermediate for complex sphingolipid and phosphatidylethanolamine (PE) synthesis or can be released from the cell where it can act via autocrine or paracrine signalling through five different G-protein coupled receptors $\left(\mathrm{S}_{1} \mathrm{PR}_{1-5}\right)(78,79)$. The exact role of S1P signalling in myeloid cells remains unclear. The treatment of LPS stimulated mouse primary microglia with the S1P structural analog fingolimod, results in the downregulation of pro-inflammatory cytokines and the upregulation of brain-derived neurotrophic factor and glial-derived neurotrophic factor (80). However, in vitro evidence suggests that both $\mathrm{S} 1 \mathrm{P}$ and fingolimod act via astrocytes, rather than myeloid cells or neurons, to suppress chronic neuroinflammation $(81,82)$. Other data suggests, instead, that signalling through $\mathrm{S}_{\mathrm{P}} \mathrm{PR}_{1-3}$ activates the $\mathrm{NF}-\kappa \mathrm{B}$ pathway and polarizes microglia towards a pro-inflammatory, amoeboid phenotype in vitro and in mouse models of cerebral ischemia (83-86). Ultimately, further research is required to elucidate the myeloid-specific role of S1P signalling in chronic neuroinflammation.

Myeloid cells express specialized scavenger receptors (SCARs) that sense and uptake extracellular lipids, including FAs. The class-B SCAR CD36, also known as FA translocase, is a phagocytic receptor that is widely expressed on microglia and peripheral myeloid cells to facilitate long chain FA uptake and low-density lipoprotein binding (87). Under demyelinating neuroinflammatory conditions, such as MS, CD36 is necessary 


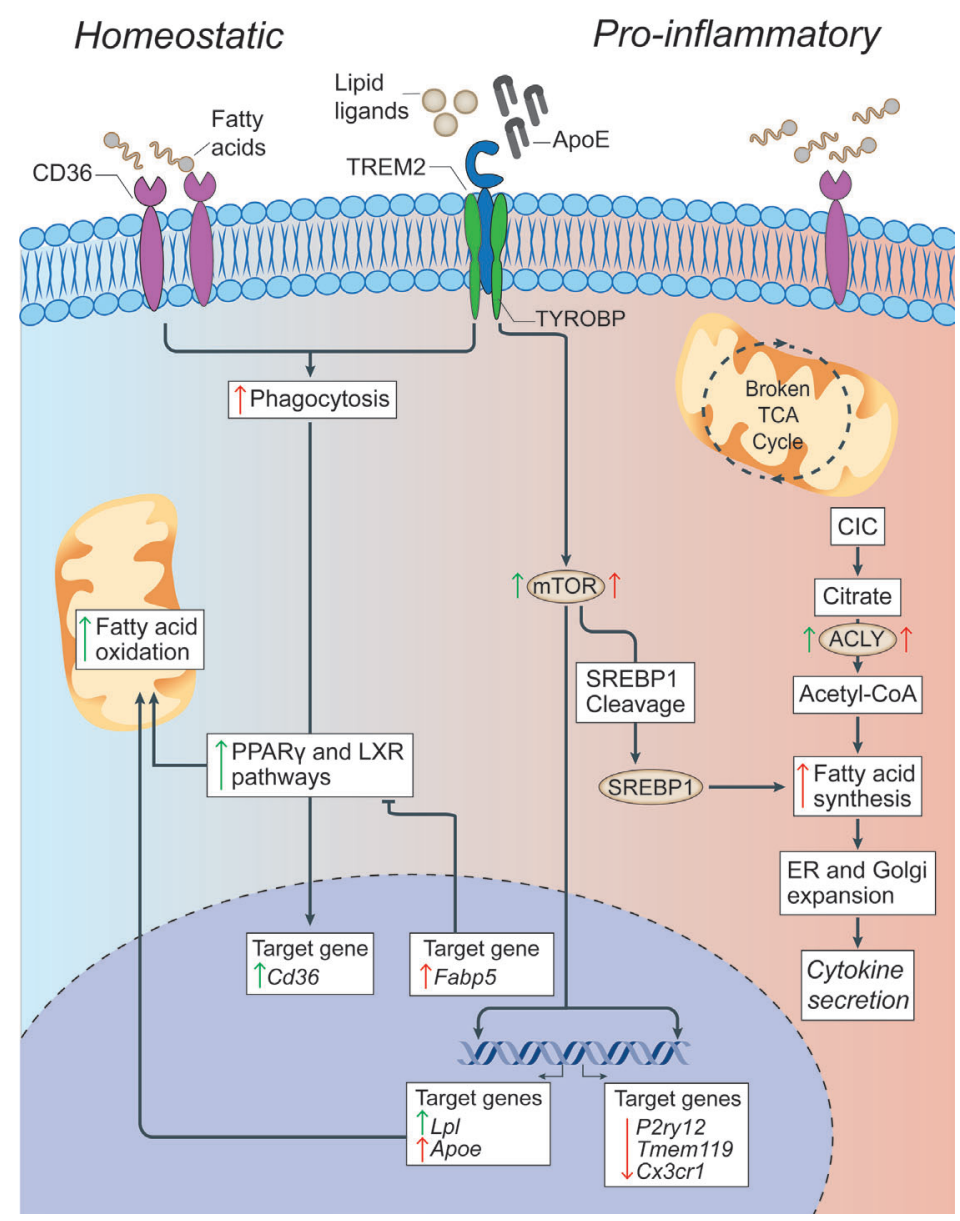

FIGURE 2 | Lipid metabolism in microglia under homeostatic and inflammatory conditions. In microglia, CD36 and TREM2 play a key role in the response to extracellular lipids. CD36 promotes lipid-responsive signalling pathways (like the PPAR $\gamma$ and LXR pathways), which in turn increase FAO and further upregulate Cd36. TREM2 activation (via ligands such as ApoE) results in the suppression of homeostatic microglial genes (P2ry12, Tmem119, and Cx3cr1), the activation of mTOR signalling, and the upregulation of lipid processing genes (such as Apoe, Lpl, and Fabp5). Despite mTOR increasing both FAS (through the cleavage and activation of SREBP-1) and glycolysis (which are canonically associated with a pro-inflammatory activation of myeloid cells), it appears that the role of TREM2 is to support correct lipid metabolism. In fact,TREM2 deficient microglia show the formation of intracellular cholesterol crystals that activate the inflammasome pathway. On the contrary, the downstream gene Fabp5 seems to play a key role in determining the pro-inflammatory activation of myeloid cells, possibly via inhibition of PPAR signalling and FAO. In pro-inflammatory microglia, a broken TCA cycle is coupled with an upregulated mitochondrial CIC, which increases citrate export from the mitochondria to the cytosol, where it is converted into acetyl-CoA for FAS by ACLY. The resultant increase in FAS supports the expansion of the ER and Golgi, and the increased production of pro-inflammatory cytokines. Green arrows = homeostatic effects. Red arrows = pro-inflammatory effects. PPAR $\gamma$, peroxisome proliferator-activated receptor $\gamma$, LXR, liver X receptor; FAO, fatty acid oxidation; mTOR, mechanistic target of rapamycin; FAS, fatty acid synthesis; ACLY, ATP citrate Iyase; CIC, citrate carrier; TCA, tricarboxylic acid cycle; SREBP-1, Sterol regulatory element binding protein 1; TYROBP, TYRO protein tyrosine kinase-binding protein; TREM2, Triggering receptor expressed on myeloid cells 2; Lpl, Lipoprotein Lipase; P2ry12, Purinergic Receptor P2Y12; Tmem119, Transmembrane Protein 119, Cx3Cr, C-X3-C Motif Chemokine Receptor 1.

for the phagocytosis of myelin debris $(88,89)$. Here, myelin internalization promotes anti-inflammatory lipid-responsive signalling pathways, like the peroxisome proliferator-activated receptor- $\gamma(\operatorname{PPAR} \gamma)$ pathway, which in turn upregulates CD36 $(88,90,91)$. This further supports the notion that CD36 serves an anti-inflammatory role as pro-inflammatory microglia have been demonstrated to downregulate $\mathrm{CD} 36$ in vivo (91) and the in vitro inhibition of CD36 in microglia and bone marrow-derived macrophages (BMDMs) promotes inflammation while reducing anti-inflammatory signalling pathways [e.g., PPAR $\gamma$ and liver $\mathrm{X}$ receptor] (88).

Another extracellular lipid sensing molecule with implications for chronic neuroinflammation is triggering receptor expressed on myeloid cells 2 (TREM2). TREM2 is a microglia-specific transmembrane receptor with several proposed ligands including ApoE (92), anionic or zwitterionic lipids, PL (93), PE, and phosphatidylserine, which become exposed on the cell surface during apoptosis (94). The binding 
of TREM2 to extracellular ligands results in the suppression of homeostatic microglial genes and a shift towards an activated phagocytic state $(74,75)$. It also leads to the activation of mTOR signalling, a pathway that has critical implications for both glycolysis (95) and lipid metabolism (95). In fact, TREM2 has emerged as an innate immune receptor that impacts microglia metabolism through the basic activation of mTOR signalling, which supports long-term cell trophism, survival, growth, and proliferation rather than drastic metabolic reprogramming (95). A recent study used cell type-specific lipidomics to demonstrate that TREM2 is not necessary for myelin uptake by microglia, rather it is required for the upregulation of lipid processing genes involved in lysosome function, cholesterol transport, and cholesterol metabolism, such as Apoe and $\operatorname{Lpl}(96,97)$. Global TREM2 deficiency hinders the efflux of cholesterol from microglia in vitro and in vivo and enhances the neurotoxic effect of cuprizone in mouse models of chronic demyelination (96).

Therefore, defective lipid metabolism in TREM2 deficient microglia could result in the accumulation of intracellular cholesterol crystals that damage lysosomes and activate the inflammasome pathway (76).

Understanding the link between lipid sensing, uptake, and intracellular metabolism is therefore key in identifying further targets for therapeutic approaches aimed at resolving chronic inflammation.

\section{LIPID METABOLISM}

FAs are transported into mitochondria and used to fuel mitochondrial OXPHOS, a process known as fatty acid $\beta$ oxidation (FAO) (Figure 2). Changes in FAO in response to inflammatory mediators has been well characterized in peripheral macrophages (98), and more recent studies in microglia have drawn many parallels between these myeloid cells. In peripheral macrophages in vivo, alternative activation via IL-4 increases FAO through PPAR $\gamma$ signalling (99). Alternatively activated microglia also increase FAO $(61,100)$, but the involvement of PPAR $\gamma$ signalling has yet to be confirmed. Most importantly, increasing FAO reduces the response to inflammatory perturbations such as LPS in SIM-A9 mouse microglia cells (101), while the inhibition of FAO in human macrophagedifferentiated THP-1 monocytic cells (102) and mice microglia in vitro and in vivo (103) has the opposite effect. Therefore, FAO positively regulates anti-inflammatory responses possibly by minimizing FA metabolites that cause endoplasmic reticulum (ER) stress and act as precursors of pro-inflammatory molecules (70). In line with this, a deficiency in lipoprotein lipase (LPL), a catalyst for the release of FAs that is required for FAO in microglia, causes a shift in microglia metabolism towards glycolysis and increased pro-inflammatory activation (100).

In addition to LPL, lipid metabolism for processes such as FAO can be facilitated through fatty acid binding proteins (FABPs). FABPs are a family of 14-15 kilodalton (kDa) lipid chaperones that reversibly bind hydrophobic molecules, including FAs, and transport them to specific nuclear compartments (104).
In homeostasis and activation, peripheral myeloid cells express the FABP isoforms FABP4 and FABP5 (105). Microglia express FABP5 only during development or upon activation (30), suggesting a specific role for FABP5 in activated microglia, which has yet to be discerned. In another type of immune cell, regulatory $\mathrm{T}$ cells (Treg), FABP5 loss of function results in decreased OXPHOS and impaired lipid metabolism, ultimately increasing Treg IL-10 production and promoting Treg immunosuppressive activity (106). Furthermore, FABP5 inhibition in $\mathrm{CD}^{+} \mathrm{T}$ cells increases PPAR $\gamma$ expression and skews $\mathrm{T}$ cell differentiation away from effector T cells (e.g., Th1, Th17) and towards Tregs in vitro (107). The same study found that systemic FABP5 inhibition reduces inflammation and improves clinical scores in mouse models of EAE (107). In FABP5 knock out BMDMs, stimulation with inflammatory (LPS and IFN- $\gamma$ ) or anti-inflammatory (IL-4) mediators results in significantly higher expression of anti-inflammatory factors $(105,108)$. These findings suggest that loss of FABP5 function promotes anti-inflammatory responses in macrophages. Thus, while little is known about the role of FABP5 in microglia, it represents an interesting target that could be manipulated to alter PPAR $\gamma$ signalling and lipid metabolism to reduce chronic neuroinflammation.

Fatty acid synthesis (FAS) is the generation of FAs from the breakdown of the metabolite acetyl-CoA and co-factor NADPH by fatty acid synthases and acetyl-CoA carboxylase in the cytoplasm. Acetyl-CoA is generated from citrate via the cytoplasmic enzyme, ATP citrate lyase (ACLY), which is activated in inflammatory macrophages (109). Of note, the role of some of these players can be ambivalent, as IL-4 stimulation of macrophages activates Akt-mTORC1 pathway to phosphorylate and activate ACLY, leading to increased histone acetylation and the upregulation of a subset of M2 genes (110). Myeloid cells challenged with LPS increase FAS through a combination of metabolic and transcriptional pathways. Metabolically, in vitro macrophages isolated from histiocytoma and treated with LPS were shown to upregulate mitochondrial citrate carrier (CIC), which exports citrate to the cytosol where it is converted into acetyl-CoA, which is then available for FAS (111). It is also known that LPS increases glycolysis in macrophages, driving flux through the PPP which increases the availability of NADPH for FAS $(112,113)$. Transcriptionally, LPS activation has been demonstrated to activate mTOR signalling in primary rat microglia and mouse N9 microglia cell lines (114). mTOR activation has been widely shown to increase FAS through the cleavage and activation of sterol regulatory element-binding protein-1, the transcriptional regulator of lipogenesis $(112,113)$.

Together, the resultant increase in FAS supports the expansion of the ER and Golgi, allowing for increased production of pro-inflammatory cytokines such as IL-6, TNF $\alpha$, and IL-12 (115). The disruption of FAS reduces both ER and Golgi expansion and pro-inflammatory cytokine secretion in DCs (115), but these findings have yet to be confirmed in myeloid cells.

The emerging field of lipidomics, the improvement of complimentary high throughput techniques, and additional 
experimental work aimed at assessing the fate of lipids in intracellular organelles (e.g., mitochondria) will reveal exciting roles for lipid metabolism in regulating myeloid cell function and, ultimately, chronic neuroinflammation.

\section{MITOCHONDRIAL DYNAMICS IN MYELOID CELLS}

Mitochondrial dynamics in tissues, including the CNS and the immune system, are regulated by complex mechanisms (116, 117). Far from being isolated organelles inside cells, mitochondria participate in an active network that is regulated by the local events of fission and fusion, as well as a global control through cellular signalling and metabolic pathways (118).

Fission is mainly controlled by the GTPase dynamin-related protein 1 (DRP1), which is further regulated by several adaptor proteins, such as the mitochondrial fission factor, as well as the mitochondrial dynamics proteins of 49 and $51 \mathrm{kDa}$ and the mitochondrial fission 1 protein (119). DRP1 functions by assembling into oligomeric spirals that constrict and cut the mitochondrion apart by working in concert with dynamin-2 (120). DRP1 activity is further controlled by post translational modifications whereby phosphorylation of serine (Ser) residues Ser 638 or Ser 616 blocks or enhances mitochondrial fission, respectively $(121,122)$. Fusion is a two-step process that is regulated by the dynamin-like GTPases mitofusin $1 / 2$ on the outer mitochondrial membrane and optic atrophy 1 (OPA1) on the inner mitochondrial membrane. Long forms (L-OPA1) are proteolytically cleaved by peptidases to generate short forms (SOPA1) to balance fusion (123). Given its location within the inner mitochondrial membrane, OPA1 plays a key role in maintaining cristae morphology, mitochondrial DNA (mtDNA), and supercomplex assembly (124). It is this fine balance between fission and fusion events that regulates key cellular processes, including mitophagy, mitochondrial transport, calcium homeostasis, and mitosis/apoptosis, thus modifying cell metabolic states via a bidirectional cross talk (125).

Upon pro-inflammatory activation, myeloid cells undergo major changes in the structure and function of their mitochondrial network that are linked with extensive metabolic rewiring (Figure 3). Activated amoeboid microglia in demyelinated cerebellar white matter show greater numbers of small and short mitochondria than the ramified microglia in wild-type (WT) mice suggesting a link between mitochondrial fission and microglial cell activation (126). Interestingly, these changes seem to partially differ between macrophages and microglia during neuroinflammation. Using $\operatorname{Ccr} 2 r f p /{ }^{+}:$: C $\times 3$ cr $1 g f p /{ }^{+}$mice, in which tissue-resident microglia and infiltrating monocyte-derived macrophages were labelled with green fluorescent protein and red fluorescent protein respectively, microglia are described to have longer and thinner mitochondria and spherical nuclei than monocyte-derived macrophages in spinal cord tissues at the onset of EAE (126).
Interfering with the mitochondrial dynamics of microglial cells has shown to affect their activation both in vitro and in vivo. In vitro studies suggest that LPS induces mitochondrial fragmentation in microglia via DRP1 signalling thus inducing mitochondrial ROS (mtROS) generation (126). Treating microglial cells in vitro with mitochondrial fission inhibitor 1 (Mdivi-1), an inhibitor of DRP1, blocks LPS-induced mitochondrial fragmentation and increases mitochondrial membrane potential, ROS production, and accumulation of intracellular TCA cycle intermediates (e.g., succinate), which is indicative of impaired OXPHOS (63). In vivo, microglia isolated from the brains of animals following induction of systemically driven neuroinflammation and con-current treatment with Mdivi-1 (from P1 to P3) show attenuated expression of genes related to pro-inflammatory activation (e.g., iNOS, Ptgs2) suggesting that controlling mitochondrial fission in vivo may intrinsically recue microglial activation (63).

Thus, modulating the mitochondrial dynamics of myeloid cells may also have extrinsic effects on neighbouring CNS cells. Indeed, fission events followed by the release of fragmented and dysfunctional microglial mitochondria propagate neuronal death through activation of naïve astrocytes to the neurotoxic A1 state (127). Following from this model, regulating fission and fusion in microglia might reduce the release of dysfunctional extracellular mitochondria, thus lessening the propagation of damage from activated microglia to astrocytes and from astrocytes to neurons. This mechanism is strictly dependent on the altered function of extracellularly released mitochondria, as intact extracellular astrocytic mitochondria instead provide neuroprotection (127129). Recent work from our group has shown that delivering functional extracellular mitochondria (via extracellular vesicles) is effective in re-establishing normal mitochondrial function in myeloid cells in vitro and in vivo during neuroinflammation (130). Further studies will be needed to identify the applicability of these findings to the cure of progressive MS and other neurodegenerative disorders (131).

\section{MITOCHONDRIAL METABOLISM OF MYELOID CELLS}

Inhibition of mitochondrial respiration drives the proinflammatory activity of myeloid cells and prevents their repolarization to an anti-inflammatory phenotype (132). Reduced OXPHOS is linked with major changes to the mitochondrial metabolism that drive diverse intracellular and extracellular signalling functions (Figure 3) (24).

The mitochondrial metabolism of myeloid cells has been thoroughly characterized in vitro using pro-inflammatory BMDMs. Carbon flux analyses have identified two "breaks" in the TCA cycle: one at the level of isocitrate dehydrogenase (IDH), the enzyme that converts isocitrate to $\alpha$-ketoglutarate $(\alpha K G)$ and another at the level of succinate dehydrogenase $(\mathrm{SDH})$, which regulates the oxidation of succinate to fumarate (133). These breaks are partially compensated for via an 


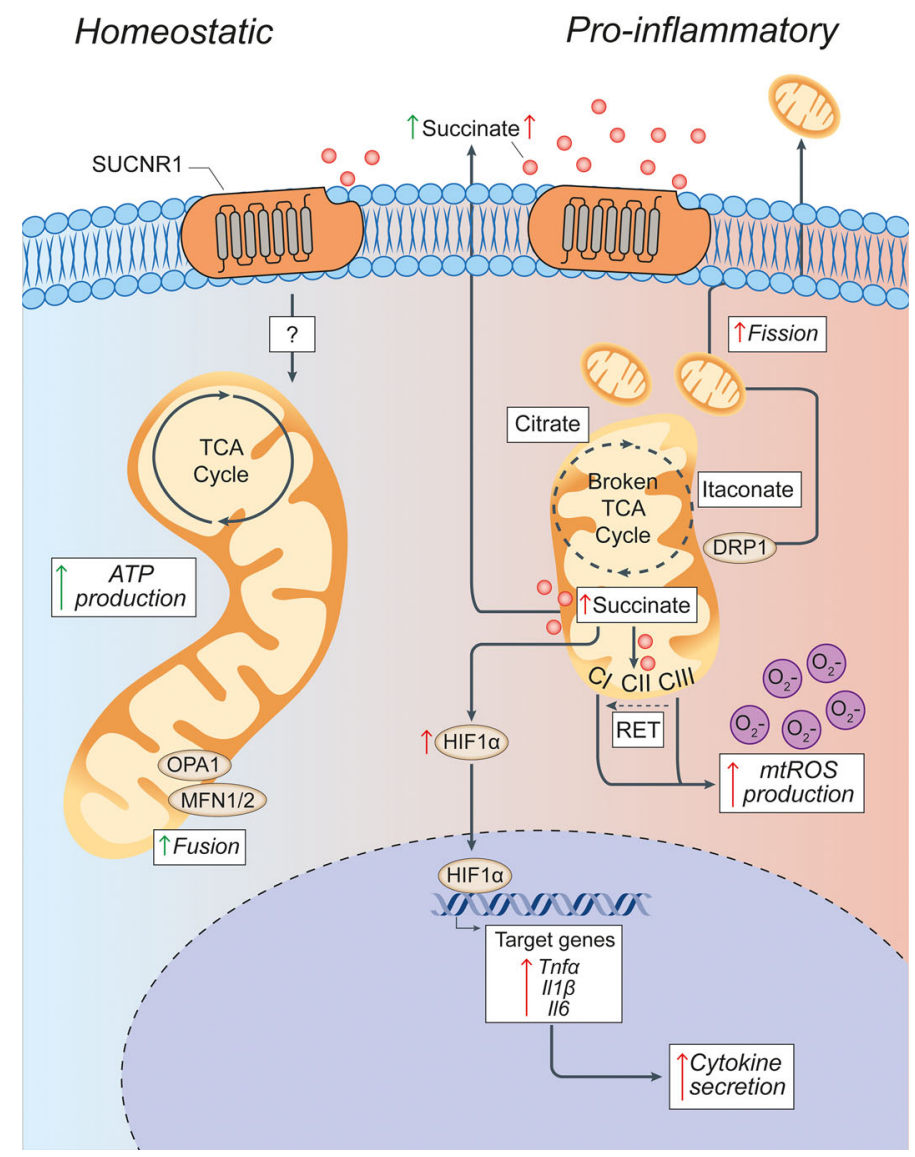

FIGURE 3 | Pro-inflammatory conditions lead to morphological and functional mitochondrial alterations of microglia. Microglia in homeostatic conditions have intact mitochondria with a functioning TCA cycle and conserved fusion of the mitochondrial network through OPA1 and MFN1/2 activities. Succinate signalling through SUCNR1 in homeostasis is presumably low, but its signalling functions in resting microglia are currently undefined. In pro-inflammatory conditions, mitochondria undergo DRP1-mediated fission and fragmentation, and show two breaks in the TCA cycle that lead to the intracellular accumulation of specific metabolites (such as succinate, citrate, and itaconate). Succinate accumulation within mitochondria can drive RET, which produces excessive mtROS through complex I. This mitochondrial dysfunction creates a pseudohypoxic state that leads to the stabilization of HIF1 $\alpha$ and enhances cytokine production and secretion. Both fragmented mitochondria and succinate can be released into the extracellular environment where succinate can signal in an autocrine or paracrine manner via SUCNR1, thus modulating both anti-inflammatory and pro-inflammatory effects. Green arrows = anti-inflammatory effects; red arrows = pro-inflammatory effects. SUCNR1, succinate receptor 1; TCA, tricarboxylic acid cycle; OPA1, optic atrophy 1; MFN1/2, mitofusin 1/2; DRP1, dynamin-related protein 1; Cl, complex I; Cll, complex II; CIII, complex III; mtROS, mitochondrial reactive oxygen species; RET, reverse electron transport; ATP, adenosine triphosphate; HIF $1 \alpha$, hypoxia inducible factor $1 \alpha$; mtROS, mitochondrial reactive oxygen species; TNF $\alpha$, tumor necrosis factor alpha; $\| 1 \beta$, interleukin-1 $\beta$; $\| 6$, interleukin-6.

enhanced arginosuccinate shunt that feeds into fumarate and malate or via increased glutaminolysis. However, they mostly lead to significant metabolic changes that include the decrease of downstream metabolites such as $\alpha \mathrm{KG}$ and fumarate, with a concomitant increase of itaconate, citrate, and succinate (24).

The increase of the expression of cis-aconitic acid decarboxylase (CAD) coded by the immunoresponsive gene 1 sustains the production of itaconate from the accumulated isocitrate $(134,135)$. Itaconate has antimicrobial properties (by inhibiting the citrate-lyase expressed by different bacterial strains) but can also act as an inhibitor of SDH, limit the levels of inflammatory cytokines, and modulate the IkBz-ATF3 inflammatory and nuclear factor erythroid 2-related factor 2
(NRF2) signalling axis $(136,137)$. Citrate, instead, is used as a precursor for FAS and lipogenesis but also for prostaglandin and nitric oxide (NO) production, thus sustaining the inflammatory activity of myeloid cells (133). Finally, succinate accumulation, which has been attributed to SDH inhibition (136), glutaminolysis replenishing $\alpha$ KG levels $(138,139)$, and the gamma-aminobutyric acid shunt (140), plays major roles in regulating both extracellular and intracellular inflammatory signalling.

Extracellularly, succinate accumulates in several inflammatory conditions, including in the cerebrospinal fluid, but not in the blood, of mice with chronic EAE (141). Extracellular succinate modulates inflammation via binding to its cognate succinate receptor 1 (SUCNR1), thus eliciting complex responses that are tissue- and context-dependent 
(142). While in DCs the succinate-SUCNR1 axis clearly potentiates the production of pro-inflammatory cytokines (143, 144), its role in the activation of other myeloid cells is still under investigation. On the one hand, a 'positive-feedback' mechanism has been described in chronic inflammation, where IL-1 $\beta$ triggers the production and release of succinate from macrophages, which in turn stimulates SUCNR1-expressing cells to maintain chronic inflammation via an autocrine and paracrine loop $(145,146)$. On the other hand, recent evidence suggests that SUCNR1 stimulation prompts an antiinflammatory phenotype on adipose tissue macrophages and tumour associated macrophages $(147,148)$.

Intracellularly, succinate regulates signalling mostly by enhancing the pro-inflammatory activity of myeloid cells. Succinate can be transported from the mitochondria via the dicarboxylic acid transporters to the cytosol where in excess it impairs prolyl hydroxylase activity by product inhibition leading to HIF- $1 \alpha$ stabilization and activation (140). This phenomenon has been defined as pseudohypoxia (149) and leads to the increased production of pro-inflammatory IL-1 $\beta$ (140). The progressive accumulation of succinate also drives the activity of $\mathrm{SDH}$, thus promoting mtROS production (150). This process links mitochondrial activity, cell metabolism, and ROS production and could be key in treating myeloid mediated oxidative injury in chronic neuroinflammation.

\section{MITOCHONDRIAL FUNCTION AND OXIDATIVE INJURY}

Recent approaches using toxic RNA sequencing (Tox-seq), which transcriptionally profiles $\mathrm{ROS}^{+}$innate immune cells, has helped to identify neurotoxic CNS innate immune populations in EAE mice (151). When $\mathrm{CD}_{1} 1 \mathrm{~b}^{+}$cells labelled for ROS production were analysed by single cell RNA sequencing, a specific $\mathrm{ROS}^{+}$microglia cluster is found to display low levels of homeostatic microglia markers (e.g., P2ry12, Sparc, Cx3cr1, and Tmem119) but high levels of oxidative stress and proinflammatory genes [e.g., NADPH oxidase subunit 2 ( $g p 91$ phox), MhcII, Il1b] (151). In addition, several genes are upregulated in $\mathrm{ROS}^{+}$microglia and macrophages throughout the oxidative stress network, including glutathione transferases (Gsto2 and Gstt2), $\gamma$-glutathione peroxidase (Gpx7), and the acivicin target genes (Ggt1 and Ggt5) (151). When EAE mice are treated with the compound acivicin, which inhibits the degradation of the antioxidant glutathione by targeting $\gamma$ glutamyl transferase, they show decreased oxidative stress and neurodegeneration, even when treatment is started 80 days after disease onset (151). These data suggest that targeting ROS production in innate immune cells is a promising strategy to treat active chronic neuroinflammation, such as that occurring in people with progressive MS.

Under inflammatory conditions, ROS are produced through various mechanisms. Cytosolic ROS are produced by the NADPH oxidase (NOX) family and NO synthases (NOS). Superoxide, $\mathrm{OH}^{-}$, and $\mathrm{H}_{2} \mathrm{O}_{2}$ are instead generated in mitochondria at mitochondrial complex I (CI) and III (CIII), which are the main sites of mtROS production $(152,153)$. Notably, a link exists between these processes where NO regulates the abundance of TCA cycle metabolites (e.g., succinate and itaconate), as well as the catalytic subunits of $\mathrm{CI}$ in inflammatory macrophages (154). This oxidative response is counterbalanced by the activity of several enzymes (e.g., catalase, superoxide dismutases, sirtuin 3), coenzymes (e.g., coenzyme Q), and metabolites (e.g., glutathione) with antioxidant activities (155). In addition, transcription factors [e.g., NRF2, Kelch Like ECH Associated Protein 1] control the expression of antioxidant genes (156), while mitochondrial transporter proteins [e.g., uncoupling protein 2] shuttle $\mathrm{H}^{+}$from the intermembrane space to the mitochondrial matrix, leading to decreased membrane potential and mtROS production (157). When these mechanisms are saturated/inhibited, excessive intracellular ROS production can impact ATP synthesis, cytokine production, mtDNA mutation, and post-translational modification of proteins (155). Extracellularly, ROS release from CNS innate immune cells maintains inflammation, while promoting neurodegeneration and demyelination (158). Given the predominant role of mitochondria in ROS production during inflammation, key potential targets for this new approach reside in specific mitochondrial proteins and complexes (Figure 3).

CI is a supercomplex of 44 subunits which form three modules: $\mathrm{N}$ module (oxidizing $\mathrm{NADH}$ and electron input), $\mathrm{Q}$ module (electron output to ubiquinone) and $\mathrm{P}$ module (proton transport) (159). CI can produce ROS when electrons circulate in the forward or reverse direction, depending on multiple factors that include mitochondrial function, cell metabolism, and cellular type (150). In fact, forward electron transport (FET) can produce proton leak from $\mathrm{CI}$, but a highly reduced pool of coenzyme $\mathrm{Q}$ and a large membrane potential can also trigger reverse electron transport (RET) from over-reduced coenzyme Q back to CI, significantly increasing superoxide production (160). During FET, blocking CI with rotenone suppresses electron transport causing electron leak and increased ROS production (161), while rotenone prevents the electron transport back from coenzyme Q and significantly reduces ROS production during RET $(152,160)$. In microglia and BMDMs, rotenone enhances ROS and pro-inflammatory cytokine production when cells are in a resting state $(162,163)$, which suggests that ROS results from impaired FET. In line with this, BMDMs displaying a knockout of the CI subunit $N d u f_{s} 4$ produce more lactate and ROS than WT BMDMs (164). However, in pro-inflammatory myeloid cells excess of the SDH substrate, succinate, stimulates RET and ultimately shifts mitochondrial activity to mtROS production (150). Accordingly, in LPS-stimulated myeloid cells, especially after prolonged treatment (8-24 h), ROS and pro-inflammatory cytokine production are reduced by rotenone, and this effect may be due to decreased RET (152). Targeting this process, without altering the normal function of CI and OXPHOS, as recently shown for ischemia reperfusion injury (165), could be key in treating chronic neuroinflammatory diseases. CIII is another key site of mtROS generation, which can be modulated. Similarly to CI, blocking CIII activity with antimycin A or myxothiazol, for 
example, in unstimulated BMDMs increases ROS production (166), while in pro-inflammatory BMDMs, blocking CIII reduced NFKB nuclear accumulation as well as ROS and proinflammatory cytokine production $(167,168)$.

Altogether these data suggest that interacting with CI or CIII (dys)functionality may be important to treat CNS inflammatory disorders. Indeed, the use of CI inhibitors such as rapamycin or metformin can inhibit mtROS production by inhibiting CI formation (169) and attenuate the induction of EAE by restricting the infiltration of mononuclear cells into the CNS and down-regulating the expression of proinflammatory cytokines (IFN $\gamma$, TNF, IL-6, IL-17, iNOS), cell adhesion molecules, and matrix metalloproteinase 9 (170).

Further studies will be needed to differentiate these effects from the pleiotropic effects that these molecules have on metabolic pathways (e.g., mTOR) and CNS cell types (e.g., oligodendrocytes) (171-174).

\section{CONCLUSION}

The growing interest in immunometabolism has demonstrated that myeloid cells are well-equipped to quickly adapt to varying environmental challenges, even when access to carbon sources is highly variable, such as in conditions of inflammation. Therapeutically attractive targets have emerged, with preliminary in vitro and in vivo testing of compounds proving to be promising. Within this framework, two routes to therapeutic relevance have emerged, targeted therapies using small molecules and compounds (175) and non-targeted therapies. In regard to the latter, the use of dietary intervention (e.g., through the ketogenic diet and/or exercise) may hold the most direct and clinically translatable therapeutic approach towards reprogramming myeloid metabolism from harmful to helpful (176). As previously discussed, microglia can utilize ketone bodies as an alternative energy substrate to glucose, and ketosis has been shown to modulate a range of microglial inflammatory processes and reduce $\mathrm{A} \beta$ and tau accumulation in $\mathrm{AD}$ mice (177). High-fat, lowcarbohydrate ketogenic diets are thought to trigger a shift from glucose metabolism towards FA metabolism, which in turn yields increased ketone body concentrations. Interestingly, pre-treatment of mice with a ketogenic diet decreased microglia activation and pro-inflammatory cytokine IL-6, IL-1 $\beta$ and TNF- $\alpha$ levels in the MPTP mouse model of PD (178). Similarly, oral administration of ketone body metabolites such as $\beta$-hydroxybutyrate have been shown to reduce microglial inflammation (179), reduce expression of pro-inflammatory cytokines IL-1 $\beta$, IL-6, CCL2/MCP-1 (180), and inhibit NLRP3 inflammasome activation (181). Metabolic

\section{REFERENCES}

1. Zhu J, Thompson CB. Metabolic Regulation of Cell Growth and Proliferation. Nat Rev Mol Cell Biol (2019) 20:436-50. doi: 10.1038/ s41580-019-0123-5

2. Chipuk JE, Mohammed JN, Gelles JD, Chen Y. Mechanistic Connections Between Mitochondrial Biology and Regulated Cell Death. Dev Cell (2021) 56(9):1221-33. doi: 10.1016/j.devcel.2021.03.033 reprogramming has been identified in exercise-related changes in cognition and immune functions, as exercise attenuated agedependent inflammatory cytokine expression and cognitive decline in mice, while decreasing glycolytic enzymes and increasing phagocytosis in isolated microglia (182).

In conclusion, the impact of metabolism on both immune and non-immune cells in neuroinflammatory conditions has seen a groundswell of interest in the past decade. Ultimately, more work must be done to fully understand how the microenvironment influences the metabolism of cells and how we can better modulate these functions.

\section{AUTHOR CONTRIBUTIONS}

LP-J designed the review outline, wrote the manuscript, and outlined the figures. CW contributed to sections of the manuscript and designed the figures. $\mathrm{RH}$ and GK contributed to sections of the manuscript and provided input for the relative figures. SP critically reviewed manuscript. All authors contributed to the article and approved the submitted version.

\section{FUNDING}

This work has received support from the National MS Society (USA; grant RG-1802-30200 to SP), the Italian Multiple Sclerosis Association (AISM, grant 2018/R/14 to SP), the United States Department of Defence (DoD) Congressionally Directed Medical Research Programs (CDMRP) (grant MS-140019 to SP), the Bascule Charitable Trust (RG 75149 and RG 98181 to SP), and Wings for Life (RG 104102 to SP). LP-J was supported by a senior research fellowship from FISM - Fondazione Italiana Sclerosi Multipla (cod. 2017/B/5) financed or co financed with the ' 5 per mille' public funding, and by a Wellcome Trust Clinical Research Career Development Fellowship (RG G105713). RH was supported by the Cambridge Trust (10468562) and is the recipient of a Canadian Scholarship Trust Foundation, an MNICambridge Douglas Avrith Graduate Studentship, and a Rosetrees Trust Studentship (A1850).

\section{ACKNOWLEDGMENTS}

The authors acknowledge the contribution of past and present members of the Pluchino laboratories, who have contributed to (or inspired) this review.

3. Balaban RS. Regulation of Oxidative Phosphorylation in the Mammalian Cell. Am J Physiol (1990) 258:C377-89. doi: 10.1152/ajpcell.1990.258.3.C377

4. Spinelli JB, Haigis MC. The Multifaceted Contributions of Mitochondria to Cellular Metabolism. Nat Cell Biol (2018) 20:745-54. doi: 10.1038/s41556018-0124-1

5. Miyazawa H, Aulehla A. Revisiting the Role of Metabolism During Development. Dev (Cambridge England) (2018) 145(19):dev131110. doi: $10.1242 /$ dev. 131110 
6. DeBerardinis RJ, Thompson CB. Cellular Metabolism and Disease: What do Metabolic Outliers Teach Us? Cell (2012) 148:1132-44. doi: 10.1016/ j.cell.2012.02.032

7. Reich DS, Lucchinetti CF, Calabresi PA. Multiple Sclerosis. New Engl J Med (2018) 378:169-80. doi: 10.1056/NEJMra1401483

8. Mallucci G, Peruzzotti-Jametti L, Bernstock JD, Pluchino S. The Role of Immune Cells, Glia and Neurons in White and Gray Matter Pathology in Multiple Sclerosis. Prog Neurobiol (2015) 127-8:1-22. doi: 10.1016/ j.pneurobio.2015.02.003

9. Faissner S, Plemel JR, Gold R, Yong VW. Progressive Multiple Sclerosis: From Pathophysiology to Therapeutic Strategies. Nat Rev Drug Discov (2019) 18:905-22. doi: 10.1038/s41573-019-0035-2

10. Brown JWL, Coles A, Horakova D, Havrdova E, Izquierdo G, Prat A, et al. Association of Initial Disease-Modifying Therapy With Later Conversion to Secondary Progressive Multiple Sclerosis. JAMA (2019) 321:175-87. doi: 10.1001/jama.2018.20588

11. Montalban X, Hauser SL, Kappos L, Arnold DL, Bar-Or A, Comi G, et al. Ocrelizumab Versus Placebo in Primary Progressive Multiple Sclerosis. N Engl J Med (2017) 376:209-20. doi: 10.1056/NEJMoa1606468

12. Kappos L, Bar-Or A, Cree BAC, Fox RJ, Giovannoni G, Gold R, et al. Siponimod Versus Placebo in Secondary Progressive Multiple Sclerosis (EXPAND): A Double-Blind, Randomised, Phase 3 Study. Lancet (2018) 391:1263-73. doi: 10.1016/S0140-6736(18)30475-6

13. Frischer JM, Weigand SD, Guo Y, Kale N, Parisi JE, Pirko I, et al. Clinical and Pathological Insights Into the Dynamic Nature of the White Matter Multiple Sclerosis Plaque. Ann Neurol (2015) 78:710-21. doi: 10.1002/ ana. 24497

14. Rissanen E, Tuisku J, Vahlberg T, Sucksdorff M, Paavilainen T, Parkkola R, et al. Microglial Activation, White Matter Tract Damage, and Disability in MS. Neurol Neuroimmunol Neuroinflamm (2018) 5:e443. doi: 10.1212/ NXI.0000000000000443

15. Brooks DJ. Imaging Approaches to Parkinson Disease. J Nucl Med Off publ Soc Nucl Med (2010) 51:596-609. doi: 10.2967/jnumed.108.059998

16. Henkel K, Karitzky J, Schmid M, Mader I, Glatting G, Unger JW, et al. Imaging of Activated Microglia With PET and [11C]PK 11195 in Corticobasal Degeneration. Mov Disord (2004) 19:817-21. doi: 10.1002/mds.20040

17. Raj D, Yin Z, Breur M, Doorduin J, Holtman IR, Olah M, et al. Increased White Matter Inflammation in Aging- and Alzheimer's Disease Brain. Front Mol Neurosci (2017) 10:206. doi: 10.3389/fnmol.2017.00206

18. Block ML, Zecca L, Hong JS. Microglia-Mediated Neurotoxicity: Uncovering the Molecular Mechanisms. Nat Rev (2007) 8:57-69. doi: 10.1038/nrn2038

19. Zrzavy T, Hametner S, Wimmer I, Butovsky O, Weiner HL, Lassmann H. Loss of 'Homeostatic' Microglia and Patterns of Their Activation in Active Multiple Sclerosis. Brain (2017) 140:1900-13. doi: 10.1093/brain/awx113

20. Bramow S, Frischer JM, Lassmann H, Koch-Henriksen N, Lucchinetti CF, Sorensen PS, et al. Demyelination Versus Remyelination in Progressive Multiple Sclerosis. Brain (2010) 133:2983-98. doi: 10.1093/brain/awq250

21. Absinta M, Sati P, Schindler M, Leibovitch EC, Ohayon J, Wu T, et al. Persistent 7-Tesla Phase Rim Predicts Poor Outcome in New Multiple Sclerosis Patient Lesions. J Clin Invest (2016) 126:2597-609. doi: 10.1172/ JCI86198

22. Absinta M, Sati P, Masuzzo F, Nair G, Sethi V, Kolb H, et al. Association of Chronic Active Multiple Sclerosis Lesions With Disability In Vivo. JAMA Neurol (2019) 76:1474-83. doi: 10.1001/jamaneurol.2019.2399

23. Elliott C, Belachew S, Wolinsky JS, Hauser SL, Kappos L, Barkhof F, et al. Chronic White Matter Lesion Activity Predicts Clinical Progression in Primary Progressive Multiple Sclerosis. Brain (2019) 142:2787-99. doi: 10.1093/brain/awz212

24. Peruzzotti-Jametti L, Pluchino S. Targeting Mitochondrial Metabolism in Neuroinflammation: Towards a Therapy for Progressive Multiple Sclerosis. Trends Mol Med (2018) 24:838-55. doi: 10.1016/j.molmed.2018.07.007

25. Louveau A, Harris TH, Kipnis J. Revisiting the Mechanisms of CNS Immune Privilege. Trends Immunol (2015) 36:569-77. doi: 10.1016/j.it.2015.08.006

26. Masuda T, Sankowski R, Staszewski O, Prinz M. Microglia Heterogeneity in the Single-Cell Era. Cell Rep (2020) 30:1271-81. doi: 10.1016/ j.celrep.2020.01.010

27. Ginhoux F, Greter M, Leboeuf M, Nandi S, See P, Gokhan S, et al. Fate Mapping Analysis Reveals That Adult Microglia Derive From Primitive
Macrophages. Sci (New York NY) (2010) 330:841-5. doi: 10.1126/ science. 1194637

28. Schulz C, Gomez Perdiguero E, Chorro L, Szabo-Rogers H, Cagnard N, Kierdorf K, et al. A Lineage of Myeloid Cells Independent of Myb and Hematopoietic Stem Cells. Sci (New York NY) (2012) 336:86-90. doi: 10.1126/science. 1219179

29. Colonna M, Butovsky O. Microglia Function in the Central Nervous System During Health and Neurodegeneration. Annu Rev Immunol (2017) 35:44168. doi: 10.1146/annurev-immunol-051116-052358

30. Hammond TR, Dufort C, Dissing-Olesen L, Giera S, Young A, Wysoker A, et al. Single-Cell RNA Sequencing of Microglia Throughout the Mouse Lifespan and in the Injured Brain Reveals Complex Cell-State Changes. Immunity (2019) 50:253-271 e6. doi: 10.1016/j.immuni.2018.11.004

31. Matcovitch-Natan O, Winter DR, Giladi A, Vargas Aguilar S, Spinrad A, Sarrazin S, et al. Microglia Development Follows a Stepwise Program to Regulate Brain Homeostasis. Sci (New York NY) (2016) 353:aad8670. doi: 10.1126/science.aad8670

32. Li Q, Cheng Z, Zhou L, Darmanis S, Neff NF, Okamoto J, et al. Developmental Heterogeneity of Microglia and Brain Myeloid Cells Revealed by Deep Single-Cell RNA Sequencing. Neuron (2019) 101:20723.e10. doi: 10.1016/j.neuron.2018.12.006

33. Rustenhoven J, Drieu A, Mamuladze T, de Lima KA, Dykstra T, Wall M, et al. Functional Characterization of the Dural Sinuses as a Neuroimmune Interface. Cell (2021) 184:1000-16.e27. doi: 10.1016/j.cell.2020.12.040

34. Mrdjen D, Pavlovic A, Hartmann FJ, Schreiner B, Utz SG, Leung BP, et al. High-Dimensional Single-Cell Mapping of Central Nervous System Immune Cells Reveals Distinct Myeloid Subsets in Health, Aging, and Disease. Immunity (2018) 48:599. doi: 10.1016/j.immuni.2018.02.014

35. Goldmann T, Wieghofer P, Jordao MJ, Prutek F, Hagemeyer N, Frenzel K, et al. Origin, Fate and Dynamics of Macrophages at Central Nervous System Interfaces. Nat Immunol (2016) 17:797-805. doi: 10.1038/ni.3423

36. Jordao MJC, Sankowski R, Brendecke SM, Sagar G, Tai YH, Tay TL, et al. Single-Cell Profiling Identifies Myeloid Cell Subsets With Distinct Fates During Neuroinflammation. Science (2019) 363(6425):eaat7554. doi: 10.1126/science.aat7554

37. Masuda T, Sankowski R, Staszewski O, Bottcher C, Amann L, Sagar, et al. Author Correction: Spatial and Temporal Heterogeneity of Mouse and Human Microglia at Single-Cell Resolution. Nature (2019) 568:E4. doi: 10.1038/s41586-019-1045-2

38. Masuda T, Sankowski R, Staszewski O, Bottcher C, Amann L, Sagar, et al. Spatial and Temporal Heterogeneity of Mouse and Human Microglia at SingleCell Resolution. Nature (2019) 566:388-92. doi: 10.1038/s41586-019-0924-x

39. Erbsloh F, Bernsmeier A, Hillesheim H. [the Glucose Consumption of the Brain \& Its Dependence on the Liver]. Arch Psychiatr Nervenkr Z Gesamte Neurol Psychiatr (1958) 196:611-26. doi: 10.1007/BF00344388

40. Mergenthaler P, Lindauer U, Dienel GA, Meisel A. Sugar for the Brain: The Role of Glucose in Physiological and Pathological Brain Function. Trends Neurosci (2013) 36:587-97. doi: 10.1016/j.tins.2013.07.001

41. Brown AM, Ransom BR. Astrocyte Glycogen as an Emergency Fuel Under Conditions of Glucose Deprivation or Intense Neural Activity. Metab Brain Dis (2015) 30:233-9. doi: 10.1007/s11011-014-9588-2

42. Brown AM, Ransom BR. Astrocyte Glycogen and Brain Energy Metabolism. Glia (2007) 55:1263-71. doi: 10.1002/glia.20557

43. Blum-Degen D, Frolich L, Hoyer S, Riederer P. Altered Regulation of Brain Glucose Metabolism as a Cause of Neurodegenerative Disorders? J Neural transm Supplementum (1995) 46:139-47.

44. Muddapu VR, Dharshini SAP, Chakravarthy VS, Gromiha MM. Neurodegenerative Diseases - Is Metabolic Deficiency the Root Cause? Front Neurosci (2020) 14:213. doi: 10.3389/fnins.2020.00213

45. Vannucci SJ, Maher F, Simpson IA. Glucose Transporter Proteins in Brain: Delivery of Glucose to Neurons and Glia. Glia (1997) 21:2-21. doi: 10.1002/ (SICI)1098-1136(199709)21:1<2::AID-GLIA2>3.0.CO;2-C

46. Wang L, Pavlou S, Du X, Bhuckory M, Xu H, Chen M. Glucose Transporter 1 Critically Controls Microglial Activation Through Facilitating Glycolysis. Mol Neurodegener (2019) 14:2. doi: 10.1186/s13024-019-0305-9

47. Lynch MA. Can the Emerging Field of Immunometabolism Provide Insights Into Neuroinflammation? Prog Neurobiol (2020) 184:101719. doi: 10.1016/ j.pneurobio.2019.101719 
48. Zhang Y, Chen K, Sloan SA, Bennett ML, Scholze AR, O'Keeffe S, et al. An RNA-Sequencing Transcriptome and Splicing Database of Glia, Neurons, and Vascular Cells of the Cerebral Cortex. J Neurosci (2014) 34:11929-47. doi: 10.1523/JNEUROSCI.1860-14.2014

49. Ghosh S, Castillo E, Frias ES, Swanson RA. Bioenergetic Regulation of Microglia. Glia (2018) 66:1200-12. doi: 10.1002/glia.23271

50. Vilalta A, Brown GC. Deoxyglucose Prevents Neurodegeneration in Culture by Eliminating Microglia. J Neuroinflamm (2014) 11:58. doi: 10.1186/17422094-11-58

51. Nagy AM, Fekete R, Horvath G, Koncsos G, Kriston C, Sebestyen A, et al. Versatility of Microglial Bioenergetic Machinery Under Starving Conditions. Biochim Biophys Acta Bioenerg (2018) 1859:201-14. doi: 10.1016/ j.bbabio.2017.12.002

52. Bernier LP, York EM, Kamyabi A, Choi HB, Weilinger NL, MacVicar BA. Microglial Metabolic Flexibility Supports Immune Surveillance of the Brain Parenchyma. Nat Commun (2020) 11:1559. doi: 10.1038/s41467-020-15267-z

53. Albrecht J, Sidoryk-Wegrzynowicz M, Zielinska M, Aschner M. Roles of Glutamine in Neurotransmission. Neuron Glia Biol (2010) 6:263-76. doi: 10.1017/S1740925X11000093

54. Hard GC. Some Biochemical Aspects of the Immune Macrophage. Br J Exp Pathol (1970) 51:97-105.

55. Newsholme P, Curi R, Gordon S, Newsholme EA. Metabolism of Glucose, Glutamine, Long-Chain Fatty Acids and Ketone Bodies by Murine Macrophages. Biochem J (1986) 239:121-5. doi: 10.1042/bj2390121

56. Wang T, Liu H, Lian G, Zhang SY, Wang X, Jiang C. Hiflalpha-Induced Glycolysis Metabolism Is Essential to the Activation of Inflammatory Macrophages. Mediators Inflammation (2017) 2017:9029327. doi: 10.1155/ 2017/9029327

57. Galvan-Pena S, O'Neill LA. Metabolic Reprograming in Macrophage Polarization. Front Immunol (2014) 5:420. doi: 10.3389/fimmu.2014.00420

58. Warburg O. On the Origin of Cancer Cells. Sci (New York NY) (1956) 123:309-14. doi: 10.1126/science.123.3191.309

59. Van den Bossche J, O'Neill LA, Menon D. Macrophage Immunometabolism: Where Are We (Going)? Trends Immunol (2017) 38:395-406. doi: 10.1016/ j.it.2017.03.001

60. Voloboueva LA, Emery JF, Sun X, Giffard RG. Inflammatory Response of Microglial BV-2 Cells Includes a Glycolytic Shift and Is Modulated by Mitochondrial Glucose-Regulated Protein 75/Mortalin. FEBS Lett (2013) 587:756-62. doi: 10.1016/j.febslet.2013.01.067

61. Gimeno-Bayon J, Lopez-Lopez A, Rodriguez MJ, Mahy N. Glucose Pathways Adaptation Supports Acquisition of Activated Microglia Phenotype. J Neurosci Res (2014) 92:723-31. doi: 10.1002/jnr.23356

62. Holland R, McIntosh AL, Finucane OM, Mela V, Rubio-Araiz A, Timmons G, et al. Inflammatory Microglia Are Glycolytic and Iron Retentive and Typify the Microglia in APP/PS1 Mice. Brain Behav Immun (2018) 68:18396. doi: 10.1016/j.bbi.2017.10.017

63. Nair S, Sobotka KS, Joshi P, Gressens P, Fleiss B, Thornton C, et al. Lipopolysaccharide-Induced Alteration of Mitochondrial Morphology Induces a Metabolic Shift in Microglia Modulating the Inflammatory Response In Vitro and In Vivo. Glia (2019) 67:1047-61. doi: 10.1002/glia.23587

64. Hu Y, Mai W, Chen L, Cao K, Zhang B, Zhang Z, et al. mTOR-mediated Metabolic Reprogramming Shapes Distinct Microglia Functions in Response to Lipopolysaccharide and ATP. Glia (2020) 68:1031-45. doi: 10.1002/ glia. 23760

65. Fodelianaki G, Lansing F, Bhattarai P, Troullinaki M, Zeballos MA, Charalampopoulos I, et al. Nerve Growth Factor Modulates LPS Induced Microglial Glycolysis and Inflammatory Responses. Exp Cell Res (2019) 377:10-6. doi: 10.1016/j.yexcr.2019.02.023

66. York EM, Zhang J, Choi HB, MacVicar BA. Neuroinflammatory Inhibition of Synaptic Long-Term Potentiation Requires Immunometabolic Reprogramming of Microglia. Glia (2021) 69:567-78. doi: 10.1002/glia.23913

67. Li Y, Lu B, Sheng L, Zhu Z, Sun H, Zhou Y, et al. Hexokinase 2-Dependent Hyperglycolysis Driving Microglial Activation Contributes to Ischemic Brain Injury. J Neurochem (2018) 144:186-200. doi: 10.1111/jnc.14267

68. Hamilton JA, Hillard CJ, Spector AA, Watkins PA. Brain Uptake and Utilization of Fatty Acids, Lipids and Lipoproteins: Application to Neurological Disorders. J Mol Neurosci (2007) 33:2-11. doi: 10.1007/ s12031-007-0060-1
69. Dimas P, Montani L, Pereira JA, Moreno D, Trötzmüller M, Gerber J, et al. CNS Myelination and Remyelination Depend on Fatty Acid Synthesis by Oligodendrocytes. Elife (2019) 8:e44702. doi: 10.7554/eLife.44702

70. Loving BA, Bruce KD. Lipid and Lipoprotein Metabolism in Microglia. Front Physiol (2020) 11:393. doi: 10.3389/fphys.2020.00393

71. Reale M, Sanchez-Ramon S. Lipids at the Cross-Road of Autoimmunity in Multiple Sclerosis. Curr med Chem (2017) 24:176-92. doi: 10.2174/ 0929867324666161123093606

72. Nogueras L, Gonzalo H, Jove M, Sol J, Gil-Sanchez A, Hervas JV, et al. Lipid Profile of Cerebrospinal Fluid in Multiple Sclerosis Patients: A Potential Tool for Diagnosis. Sci Rep (2019) 9:11313. doi: 10.1038/s41598-019-47906-x

73. Chausse B, Kakimoto PA, Kann O. Microglia and Lipids: How Metabolism Controls Brain Innate Immunity. Semin Cell Dev Biol (2021) 112:137-44. doi: 10.1016/j.semcdb.2020.08.001

74. Krasemann S, Madore C, Cialic R, Baufeld C, Calcagno N, El Fatimy R, et al. The TREM2-APOE Pathway Drives the Transcriptional Phenotype of Dysfunctional Microglia in Neurodegenerative Diseases. Immunity (2017) 47:566-81.e9. doi: 10.1016/j.immuni.2017.08.008

75. Keren-Shaul H, Spinrad A, Weiner A, Matcovitch-Natan O, Dvir-Szternfeld R, Ulland TK, et al. A Unique Microglia Type Associated With Restricting Development of Alzheimer's Disease. Cell (2017) 169:1276-90.e17. doi: 10.1016/j.cell.2017.05.018

76. Cantuti-Castelvetri L, Fitzner D, Bosch-Queralt M, Weil M-T, Su M, Sen P, et al. Defective Cholesterol Clearance Limits Remyelination in the Aged Central Nervous System. Science (2018) 359:684. doi: 10.1126/science.aan4183

77. Bogie JFJ, Grajchen E, Wouters E, Corrales AG, Dierckx T, Vanherle S, et al. Stearoyl-CoA Desaturase-1 Impairs the Reparative Properties of Macrophages and Microglia in the Brain. J Exp Med (2020) 217(5): e20191660. doi: 10.1084/jem.20191660

78. Proia RL, Hla T. Emerging Biology of Sphingosine-1-Phosphate: Its Role in Pathogenesis and Therapy. J Clin Invest (2015) 125:1379-87. doi: 10.1172/ JCI76369

79. Mendelson K, Evans T, Hla T. Sphingosine 1-Phosphate Signalling. Development (2014) 141:5-9. doi: 10.1242/dev.094805

80. Noda H, Takeuchi H, Mizuno T, Suzumura A. Fingolimod Phosphate Promotes the Neuroprotective Effects of Microglia. J Neuroimmunology (2013) 256:13-8. doi: 10.1016/j.jneuroim.2012.12.005

81. Rothhammer V, Kenison JE, Tjon E, Takenaka MC, de Lima KA, Borucki $\mathrm{DM}$, et al. Sphingosine 1-Phosphate Receptor Modulation Suppresses Pathogenic Astrocyte Activation and Chronic Progressive CNS Inflammation. Proc Natl Acad Sci (2017) 114:2012. doi: 10.1073/ pnas. 1615413114

82. Tran C, Heng B, Teo JD, Humphrey SJ, Qi Y, Couttas TA, et al. Sphingosine 1-Phosphate But Not Fingolimod Protects Neurons Against Excitotoxic Cell Death by Inducing Neurotrophic Gene Expression in Astrocytes. J Neurochem (2020) 153:173-88. doi: 10.1111/jnc.14917

83. Gaire BP, Lee C-H, Sapkota A, Lee SY, Chun J, Cho HJ, et al. AndIdentification of Sphingosine 1-Phosphate Receptor Subtype 1 (S1P1) as a Pathogenic Factor in Transient Focal Cerebral Ischemia. Mol Neurobiol (2018) 55:2320-32. doi: 10.1007/s12035-017-0468-8

84. Gaire BP, Song M-R, Choi JW. Sphingosine 1-Phosphate Receptor Subtype 3 (S1P3) Contributes to Brain Injury After Transient Focal Cerebral Ischemia Via Modulating Microglial Activation and Their M1 Polarization. J Neuroinflamm (2018) 15:284. doi: 10.1186/s12974-018-1323-1

85. Sapkota A, Gaire BP, Kang M-G, Choi JW. S1P2 Contributes to Microglial Activation and M1 Polarization Following Cerebral Ischemia Through ERK1/2 and JNK. Sci Rep (2019) 9:12106. doi: 10.1038/s41598-019-48609-Z

86. Karunakaran I, Alam S, Jayagopi S, Frohberger SJ, Hansen JN, Kuehlwein J, et al. Neural Sphingosine 1-Phosphate Accumulation Activates Microglia and Links Impaired Autophagy and Inflammation. Glia (2019) 67:1859-72. doi: 10.1002/glia.23663

87. Coraci IS, Husemann J, Berman JW, Hulette C, Dufour JH, Campanella GK, et al. CD36, a Class B Scavenger Receptor, Is Expressed on Microglia in Alzheimer's Disease Brains and Can Mediate Production of Reactive Oxygen Species in Response to X3b2;-Amyloid Fibrils. Am J Pathol (2002) 160:10112. doi: $10.1016 /$ S0002-9440(10)64354-4

88. Grajchen E, Wouters E, van de Haterd B, Haidar M, Hardonnière K, Dierckx T, et al. CD36-Mediated Uptake of Myelin Debris by Macrophages and 
Microglia Reduces Neuroinflammation. J Neuroinflamm (2020) 17:224. doi: 10.1186/s12974-020-01899-x

89. Safaiyan S, Kannaiyan N, Snaidero N, Brioschi S, Biber K, Yona S, et al. AgeRelated Myelin Degradation Burdens the Clearance Function of Microglia During Aging. Nat Neurosci (2016) 19:995-8. doi: 10.1038/nn.4325

90. Nagy L, Tontonoz P, Alvarez JGA, Chen H, Evans RM. Oxidized LDL Regulates Macrophage Gene Expression Through Ligand Activation of PPAR 7 . Cell (1998) 93:229-40. doi: 10.1016/S0092-8674(00)81574-3

91. Dobri A-M, Dudău M, Enciu A-M, Hinescu ME. CD36 in Alzheimer's Disease: An Overview of Molecular Mechanisms and Therapeutic Targeting. Neuroscience (2021) 453:301-11. doi: 10.1016/j.neuroscience.2020.11.003

92. Atagi Y, Liu C-C, Painter MM, Chen X-F, Verbeeck C, Zheng H, et al. Apolipoprotein E Is a Ligand for Triggering Receptor Expressed on Myeloid Cells 2 (Trem2)*. J Biol Chem (2015) 290:26043-50. doi: 10.1074/jbc.M115.679043

93. Wang Y, Cella M, Mallinson K, Ulrich JD, Young KL, Robinette ML, et al. Trem2 Lipid Sensing Sustains the Microglial Response in An Alzheimer's Disease Model. Cell (2015) 160:1061-71. doi: 10.1016/j.cell.2015.01.049

94. Shirotani K, Hori Y, Yoshizaki R, Higuchi E, Colonna M, Saito T, et al. Aminophospholipids Are Signal-Transducing TREM2 Ligands on Apoptotic Cells. Sci Rep (2019) 9:7508. doi: 10.1038/s41598-019-43535-6

95. Ulland TK, Song WM, Huang SC, Ulrich JD, Sergushichev A, Beatty WL, et al. Trem2 Maintains Microglial Metabolic Fitness in Alzheimer's Disease. Cell (2017) 170:649-63.e13. doi: 10.1016/j.cell.2017.07.023

96. Nugent AA, Lin K, van Lengerich B, Lianoglou S, Przybyla L, Davis SS, et al. Trem2 Regulates Microglial Cholesterol Metabolism Upon Chronic Phagocytic Challenge. Neuron (2020) 105:837-54.e9. doi: 10.1016/ j.neuron.2019.12.007

97. Poliani PL, Wang Y, Fontana E, Robinette ML, Yamanishi Y, Gilfillan S, et al. TREM2 Sustains Microglial Expansion During Aging and Response to Demyelination. J Clin Invest (2015) 125:2161-70. doi: 10.1172/JCI77983

98. Batista-Gonzalez A, Vidal R, Criollo A, Carreno LJ. New Insights on the Role of Lipid Metabolism in the Metabolic Reprogramming of Macrophages. Front Immunol (2019) 10:2993. doi: 10.3389/fimmu.2019.02993

99. Namgaladze D, Brüne B. Macrophage Fatty Acid Oxidation and its Roles in Macrophage Polarization and Fatty Acid-Induced Inflammation. Biochim Biophys Acta (BBA) - Mol Cell Biol Lipids (2016) 1861:1796-807. doi: 10.1016/j.bbalip.2016.09.002

100. Bruce KD, Gorkhali S, Given K, Coates AM, Boyle KE, Macklin WB, et al. Lipoprotein Lipase is a Feature of Alternatively-Activated Microglia and May Facilitate Lipid Uptake in the CNS During Demyelination. Front Mol Neurosci (2018) 11:57. doi: 10.3389/fnmol.2018.00057

101. Gill EL, Raman S, Yost RA, Garrett TJ, Vedam-Mai V. L-Carnitine Inhibits Lipopolysaccharide-Induced Nitric Oxide Production of SIM-A9 Microglia Cells. ACS Chem Neurosci (2018) 9:901-5. doi: 10.1021/acschemneuro.7b00468

102. Namgaladze D, Lips S, Leiker TJ, Murphy RC, Ekroos K, Ferreiros N, et al. Inhibition of Macrophage Fatty Acid $\beta$-Oxidation Exacerbates PalmitateInduced Inflammatory and Endoplasmic Reticulum Stress Responses. Diabetologia (2014) 57:1067-77. doi: 10.1007/s00125-014-3173-4

103. Beckers L, Geric I, Stroobants S, Beel S, Van Damme P, D’Hooge R, et al. Microglia Lacking a Peroxisomal $\beta$-Oxidation Enzyme Chronically Alter Their Inflammatory Profile Without Evoking Neuronal and Behavioral Deficits. J Neuroinflamm (2019) 16:61. doi: 10.1186/s12974-019-1442-3

104. Furuhashi M, Hotamisligil GS. Fatty Acid-Binding Proteins: Role in Metabolic Diseases and Potential as Drug Targets. Nat Rev Drug Discov (2008) 7:489-503. doi: 10.1038/nrd2589

105. Moore SM, Holt VV, Malpass LR, Hines IN, Wheeler MD. Fatty Acid-Binding Protein 5 Limits the Anti-Inflammatory Response in Murine Macrophages. Mol Immunol (2015) 67:265-75. doi: 10.1016/j.molimm.2015.06.001

106. Field CS, Baixauli F, Kyle RL, Puleston DJ, Cameron AM, Sanin DE, et al. Mitochondrial Integrity Regulated by Lipid Metabolism Is a Cell-Intrinsic Checkpoint for Treg Suppressive Function. Cell Metab (2020) 31:422-37.e5. doi: 10.1016/j.cmet.2019.11.021

107. Rao E, Singh P, Li Y, Zhang Y, Chi YI, Suttles J, et al. Targeting Epidermal Fatty Acid Binding Protein for Treatment of Experimental Autoimmune Encephalomyelitis. BMC Immunol (2015) 16:28. doi: 10.1186/s12865-0150091-2

108. Zhang Y, Sun Y, Rao E, Yan F, Li Q, Zhang Y, et al. Fatty Acid-Binding Protein E-FABP Restricts Tumor Growth by Promoting IFN- $\beta$ Responses in
Tumor-Associated Macrophages. Cancer Res (2014) 74:2986-98. doi: 10.1158/0008-5472.CAN-13-2689

109. Baardman J, Verberk SGS, van der Velden S, Gijbels MJJ, van Roomen CPPA, Sluimer JC, et al. Macrophage ATP Citrate Lyase Deficiency Stabilizes Atherosclerotic Plaques. Nat Commun (2020) 11:6296. doi: 10.1038/s41467020-20141-z

110. Covarrubias AJ, Aksoylar HI, Yu J, Snyder NW, Worth AJ, Iyer SS, et al. AktmTORC1 Signaling Regulates Acly to Integrate Metabolic Input to Control of Macrophage Activation. eLife (2016) 5:e11612. doi: 10.7554/eLife.11612

111. Infantino V, Convertini P, Cucci L, Panaro MA, Di Noia MA, Calvello R, et al. The Mitochondrial Citrate Carrier: A New Player in Inflammation. Biochem J (2011) 438:433-6. doi: 10.1042/BJ20111275

112. Laplante M, Sabatini DM. An Emerging Role of mTOR in Lipid Biosynthesis. Curr Biol (2009) 19:R1046-52. doi: 10.1016/j.cub.2009.09.058

113. Covarrubias AJ, Aksoylar HI, Horng T. Control of Macrophage Metabolism and Activation by mTOR and Akt Signaling. Semin Immunol (2015) 27:28696. doi: 10.1016/j.smim.2015.08.001

114. Ye X, Zhu M, Che X, Wang H, Liang X-J, Wu C, et al. Lipopolysaccharide Induces Neuroinflammation in Microglia by Activating the MTOR Pathway and Downregulating Vps34 to Inhibit Autophagosome Formation. J Neuroinflamm (2020) 17:18. doi: 10.1186/s12974-019-1644-8

115. Everts B, Amiel E, Huang SC-C, Smith AM, Chang C-H, Lam WY, et al. TLR-Driven Early Glycolytic Reprogramming Via the Kinases TBK1-IKKe Supports the Anabolic Demands of Dendritic Cell Activation. Nat Immunol (2014) 15:323-32. doi: 10.1038/ni.2833

116. Bertholet AM, Delerue T, Millet AM, Moulis MF, David C, Daloyau M, et al. Mitochondrial Fusion/Fission Dynamics in Neurodegeneration and Neuronal Plasticity. Neurobiol Dis (2016) 90:3-19. doi: 10.1016/j.nbd.2015.10.011

117. Rambold AS, Pearce EL. Mitochondrial Dynamics at the Interface of Immune Cell Metabolism and Function. Trends Immunol (2018) 39:6-18. doi: 10.1016/j.it.2017.08.006

118. Braschi E, McBride HM. Mitochondria and the Culture of the Borg: Understanding the Integration of Mitochondrial Function Within the Reticulum, the Cell, and the Organism. BioEssays News Rev mol Cell Dev Biol (2010) 32:958-66. doi: 10.1002/bies.201000073

119. Labbe K, Murley A, Nunnari J. Determinants and Functions of Mitochondrial Behavior. Annu Rev Cell Dev Biol (2014) 30:357-91. doi: 10.1146/annurev-cellbio-101011-155756

120. Lee JE, Westrate LM, Wu H, Page C, Voeltz GK. Multiple Dynamin Family Members Collaborate to Drive Mitochondrial Division. Nature (2016) 540:139-43. doi: 10.1038/nature20555

121. Cereghetti GM, Stangherlin A, Martins de Brito O, Chang CR, Blackstone C, Bernardi P, et al. Dephosphorylation by Calcineurin Regulates Translocation of Drp1 to Mitochondria. Proc Natl Acad Sci U S A (2008) 105:15803-8. doi: 10.1073/pnas.0808249105

122. Jahani-Asl A, Slack RS. The Phosphorylation State of Drp1 Determines Cell Fate. EMBO Rep (2007) 8:912-3. doi: 10.1038/sj.embor.7401077

123. Anand R, Wai T, Baker MJ, Kladt N, Schauss AC, Rugarli E, et al. The i-AAA Protease YME1L and OMA1 Cleave OPA1 to Balance Mitochondrial Fusion and Fission. J Cell Biol (2014) 204:919-29. doi: 10.1083/jcb.201308006

124. Cogliati S, Frezza C, Soriano ME, Varanita T, Quintana-Cabrera R, Corrado M, et al. Mitochondrial Cristae Shape Determines Respiratory Chain Supercomplexes Assembly and Respiratory Efficiency. Cell (2013) 155:16071. doi: $10.1016 /$ j.cell.2013.08.032

125. Mishra P, Chan DC. Metabolic Regulation of Mitochondrial Dynamics. J Cell Biol (2016) 212:379-87. doi: 10.1083/jcb.201511036

126. Katoh M, Wu B, Nguyen HB, Thai TQ, Yamasaki R, Lu H, et al. Polymorphic Regulation of Mitochondrial Fission and Fusion Modifies Phenotypes of Microglia in Neuroinflammation. Sci Rep (2017) 7:4942. doi: 10.1038/s41598-017-05232-0

127. Joshi AU, Minhas PS, Liddelow SA, Haileselassie B, Andreasson KI, Dorn GW2nd, et al. Fragmented Mitochondria Released From Microglia Trigger A1 Astrocytic Response and Propagate Inflammatory Neurodegeneration. Nat Neurosci (2019) 22:1635-48. doi: 10.1038/s41593-019-0486-0

128. Hayakawa K, Esposito E, Wang X, Terasaki Y, Liu Y, Xing C, et al. Transfer of Mitochondria From Astrocytes to Neurons After Stroke. Nature (2016) 535:551-5. doi: 10.1038/nature18928

129. Pluchino S, Peruzzotti-Jametti L, Frezza C. Astrocyte Power Fuels Neurons During Stroke. Swiss Med Wkly (2016) 146:w14374. doi: 10.4414/smw.2016.14374 
130. Peruzzotti-Jametti L, Bernstock JD, Willis CM, Manferrari G, Rogall R, Fernandez-Vizarra E, et al. Neural Stem Cells Traffic Functional Mitochondria Via Extracellular Vesicles. PloS Biol (2021) 19:e3001166. doi: 10.1371/journal.pbio.3001166

131. Pluchino S, Smith JA, Peruzzotti-Jametti L. Promises and Limitations of Neural Stem Cell Therapies for Progressive Multiple Sclerosis. Trends Mol Med (2020) 26(10):898-912. doi: 10.1016/j.molmed.2020.04.005

132. Van den Bossche J, Baardman J, Otto NA, van der Velden S, Neele AE, van den Berg SM, et al. Mitochondrial Dysfunction Prevents Repolarization of Inflammatory Macrophages. Cell Rep (2016) 17:684-96. doi: 10.1016/ j.celrep.2016.09.008

133. Jha AK, Huang SC, Sergushichev A, Lampropoulou V, Ivanova $Y$, Loginicheva E, et al. Network Integration of Parallel Metabolic and Transcriptional Data Reveals Metabolic Modules That Regulate Macrophage Polarization. Immunity (2015) 42:419-30. doi: 10.1016/j.immuni.2015.02.005

134. Tallam A, Perumal TM, Antony PM, Jager C, Fritz JV, Vallar L, et al. Gene Regulatory Network Inference of Immunoresponsive Gene 1 (Irg1) Identifies Interferon Regulatory Factor 1 (IRF1) as Its Transcriptional Regulator in Mammalian Macrophages. PloS One (2016) 11:e0149050. doi: 10.1371/ journal.pone. 0149050

135. Michelucci A, Cordes T, Ghelfi J, Pailot A, Reiling N, Goldmann O, et al. Immune-Responsive Gene 1 Protein Links Metabolism to Immunity by Catalyzing Itaconic Acid Production. Proc Natl Acad Sci USA (2013) 110:7820-5. doi: 10.1073/pnas.1218599110

136. Lampropoulou V, Sergushichev A, Bambouskova M, Nair S, Vincent EE, Loginicheva E, et al. Itaconate Links Inhibition of Succinate Dehydrogenase With Macrophage Metabolic Remodeling and Regulation of Inflammation. Cell Metab (2016) 24:158-66. doi: 10.1016/j.cmet.2016.06.004

137. Bambouskova M, Gorvel L, Lampropoulou V, Sergushichev A, Loginicheva E, Johnson K, et al. Electrophilic Properties of Itaconate and Derivatives Regulate the IkappaBzeta-ATF3 Inflammatory Axis. Nature (2018) 556:5014. doi: 10.1038/s41586-018-0052-z

138. Palsson-McDermott EM, O'Neill LA. The Warburg Effect Then and Now: From Cancer to Inflammatory Diseases. Bioessays (2013) 35:965-73. doi: 10.1002/bies.201300084

139. Fedotcheva NI, Sokolov AP, Kondrashova MN. Nonezymatic Formation of Succinate in Mitochondria Under Oxidative Stress. Free Radic Biol Med (2006) 41:56-64. doi: 10.1016/j.freeradbiomed.2006.02.012

140. Tannahill GM, Curtis AM, Adamik J, Palsson-McDermott EM, McGettrick AF, Goel G, et al. Succinate is an Inflammatory Signal That Induces IL-1beta Through HIF-1alpha. Nature (2013) 496:238-42. doi: 10.1038/nature11986

141. Peruzzotti-Jametti L, Bernstock JD, Vicario N, Costa ASH, Kwok CK, Leonardi T, et al. Macrophage-Derived Extracellular Succinate Licenses Neural Stem Cells to Suppress Chronic Neuroinflammation. Cell Stem Cell (2018) 22:355-68.e13. doi: 10.1016/j.stem.2018.01.020

142. Krzak G, Willis CM, Smith JA, Pluchino S, Peruzzotti-Jametti L. Succinate Receptor 1: An Emerging Regulator of Myeloid Cell Function in Inflammation. Trends Immunol (2021) 42:45-58. doi: 10.1016/j.it.2020.11.004

143. Rubic T, Lametschwandtner G, Jost S, Hinteregger S, Kund J, CarballidoPerrig N, et al. Triggering the Succinate Receptor GPR91 on Dendritic Cells Enhances Immunity. Nat Immunol (2008) 9:1261-9. doi: 10.1038/ni.1657

144. Saraiva AL, Veras FP, Peres RS, Talbot J, de Lima KA, Luiz JP, et al. Succinate Receptor Deficiency Attenuates Arthritis by Reducing Dendritic Cell Traffic and Expansion of Th17 Cells in the Lymph Nodes. FASEB J Off Publ Fed Am Soc Exp Biol (2018) 12:fj201800285. doi: 10.1096/fj.201800285

145. Littlewood-Evans A, Sarret S, Apfel V, Loesle P, Dawson J, Zhang J, et al. GPR91 Senses Extracellular Succinate Released From Inflammatory Macrophages and Exacerbates Rheumatoid Arthritis. J Exp Med (2016) 213:1655-62. doi: 10.1084/jem.20160061

146. van Diepen JA, Robben JH, Hooiveld GJ, Carmone C, Alsady M, Boutens L, et al. SUCNR1-Mediated Chemotaxis of Macrophages Aggravates ObesityInduced Inflammation and Diabetes. Diabetologia (2017) 60:1304-13. doi: $10.1007 / \mathrm{s} 00125-017-4261-\mathrm{z}$

147. Keiran N, Ceperuelo-Mallafre V, Calvo E, Hernandez-Alvarez MI, Ejarque M, Nunez-Roa C, et al. SUCNR1 Controls an Anti-Inflammatory Program in Macrophages to Regulate the Metabolic Response to Obesity. Nat Immunol (2019) 20:581-92. doi: 10.1038/s41590-019-0372-7
148. Wu JY, Huang TW, Hsieh YT, Wang YF, Yen CC, Lee GL, et al. CancerDerived Succinate Promotes Macrophage Polarization and Cancer Metastasis Via Succinate Receptor. Mol Cell (2020) 77:213-27.e5. doi: 10.1016/j.molcel.2019.10.023

149. Selak MA, Armour SM, MacKenzie ED, Boulahbel H, Watson DG, Mansfield $\mathrm{KD}$, et al. Succinate Links TCA Cycle Dysfunction to Oncogenesis by Inhibiting HIF-Alpha Prolyl Hydroxylase. Cancer Cell (2005) 7:77-85. doi: 10.1016/j.ccr.2004.11.022

150. Mills EL, Kelly B, Logan A, Costa AS, Varma M, Bryant CE, et al. Succinate Dehydrogenase Supports Metabolic Repurposing of Mitochondria to Drive Inflammatory Macrophages. Cell (2016) 167:457-70.e13. doi: 10.1016/ j.cell.2016.08.064

151. Mendiola AS, Ryu JK, Bardehle S, Meyer-Franke A, Ang KK, Wilson C, et al. Transcriptional Profiling and Therapeutic Targeting of Oxidative Stress in Neuroinflammation. Nat Immunol (2020) 21:513-24. doi: 10.1038/s41590020-0654-0

152. Zuo H, Wan Y. Metabolic Reprogramming in Mitochondria of Myeloid Cells. Cells (2019) 9(1):5. doi: 10.3390/cells9010005

153. Murphy MP. How Mitochondria Produce Reactive Oxygen Species. Biochem $J$ (2009) 417:1-13. doi: 10.1042/BJ20081386

154. Bailey JD, Diotallevi M, Nicol T, McNeill E, Shaw A, Chuaiphichai S, et al. Nitric Oxide Modulates Metabolic Remodeling in Inflammatory Macrophages Through TCA Cycle Regulation and Itaconate Accumulation. Cell Rep (2019) 28:218-30.e7. doi: 10.1016/j.celrep.2019.06.018

155. Angajala A, Lim S, Phillips JB, Kim JH, Yates C, You Z, et al. Diverse Roles of Mitochondria in Immune Responses: Novel Insights Into ImmunoMetabolism. Front Immunol (2018) 9:1605. doi: 10.3389/fimmu.2018.01605

156. Motohashi H, Yamamoto M. Nrf2-Keap1 Defines a Physiologically Important Stress Response Mechanism. Trends Mol Med (2004) 10:54957. doi: 10.1016/j.molmed.2004.09.003

157. Emre Y, Nubel T. Uncoupling Protein UCP2: When Mitochondrial Activity Meets Immunity. FEBS Lett (2010) 584:1437-42. doi: 10.1016/j.febslet.2010.03.014

158. Fischer MT, Sharma R, Lim JL, Haider L, Frischer JM, Drexhage J, et al. NADPH Oxidase Expression in Active Multiple Sclerosis Lesions in Relation to Oxidative Tissue Damage and Mitochondrial Injury. Brain (2012) 135:886-99. doi: 10.1093/brain/aws012

159. Guerrero-Castillo S, Baertling F, Kownatzki D, Wessels HJ, Arnold S, Brandt $\mathrm{U}$, et al. The Assembly Pathway of Mitochondrial Respiratory Chain Complex I. Cell Metab (2017) 25:128-39. doi: 10.1016/j.cmet.2016.09.002

160. Scialo F, Fernandez-Ayala DJ, Sanz A. Role of Mitochondrial Reverse Electron Transport in ROS Signaling: Potential Roles in Health and Disease. Front Physiol (2017) 8:428. doi: 10.3389/fphys.2017.00428

161. Li N, Ragheb K, Lawler G, Sturgis J, Rajwa B, Melendez JA, et al. Mitochondrial Complex I Inhibitor Rotenone Induces Apoptosis Through Enhancing Mitochondrial Reactive Oxygen Species Production. J Biol Chem (2003) 278:8516-25. doi: 10.1074/jbc.M210432200

162. Gao F, Chen D, Hu Q, Wang G. Rotenone Directly Induces BV2 Cell Activation Via the P38 MAPK Pathway. PloS One (2013) 8:e72046. doi: 10.1371/journal.pone.0072046

163. Garaude J, Acin-Perez R, Martinez-Cano S, Enamorado M, Ugolini M, Nistal-Villan E, et al. Mitochondrial Respiratory-Chain Adaptations in Macrophages Contribute to Antibacterial Host Defense. Nat Immunol (2016) 17:1037-45. doi: 10.1038/ni.3509

164. Jin Z, Wei W, Yang M, Du Y, Wan Y. Mitochondrial Complex I Activity Suppresses Inflammation and Enhances Bone Resorption by Shifting Macrophage-Osteoclast Polarization. Cell Metab (2014) 20:483-98. doi: 10.1016/j.cmet.2014.07.011

165. Yin Z, Burger N, Kula-Alwar D, Aksentijevic D, Bridges HR, Prag HA, et al. Structural Basis for a Complex I Mutation That Blocks Pathological ROS Production. Nat Commun (2021) 12:707. doi: 10.1038/s41467-021-20942-w

166. Bleier L, Drose S. Superoxide Generation by Complex III: From Mechanistic Rationales to Functional Consequences. Biochim Biophys Acta (2013) 1827:1320-31. doi: 10.1016/j.bbabio.2012.12.002

167. Zmijewski JW, Lorne E, Banerjee S, Abraham E. Participation of Mitochondrial Respiratory Complex III in Neutrophil Activation and Lung Injury. Am J Physiol Lung Cell Mol Physiol (2009) 296:L624-34. doi: 10.1152/ajplung.90522.2008 
168. Cameron AM, Castoldi A, Sanin DE, Flachsmann LJ, Field CS, Puleston DJ, et al. Inflammatory Macrophage Dependence on $\mathrm{NAD}(+)$ Salvage is a Consequence of Reactive Oxygen Species-Mediated DNA Damage. Nat Immunol (2019) 20:420-32. doi: 10.1038/s41590-019-0336-y

169. Miwa S, Jow H, Baty K, Johnson A, Czapiewski R, Saretzki G, et al. Low Abundance of the Matrix Arm of Complex I in Mitochondria Predicts Longevity in Mice. Nat Commun (2014) 5:3837. doi: 10.1038/ncomms4837

170. Nath N, Khan M, Paintlia MK, Singh I, Hoda MN, Giri S. Metformin Attenuated the Autoimmune Disease of the Central Nervous System in Animal Models of Multiple Sclerosis. J Immunol (2009) 182:8005-14. doi: 10.4049/jimmunol.0803563

171. Neumann B, Baror R, Zhao C, Segel M, Dietmann S, Rawji KS, et al. Metformin Restores Cns Remyelination Capacity by Rejuvenating Aged Stem Cells. Cell Stem Cell (2019) 25:473-85.e8. doi: 10.1016/j.stem.2019.08.015

172. Dziedzic A, Saluk-Bijak J, Miller E, Bijak M. Metformin as a Potential Agent in the Treatment of Multiple Sclerosis. Int J Mol Sci (2020) 21. doi: 10.3390/ ijms 21175957

173. Sun Y, Tian T, Gao J, Liu X, Hou H, Cao R, et al. Metformin Ameliorates the Development of Experimental Autoimmune Encephalomyelitis by Regulating T Helper 17 and Regulatory T Cells in Mice. J Neuroimmunol (2016) 292:58-67. doi: 10.1016/j.jneuroim.2016.01.014

174. Paintlia AS, Paintlia MK, Mohan S, Singh AK, Singh I. AMP-Activated Protein Kinase Signaling Protects Oligodendrocytes That Restore Central Nervous System Functions in an Experimental Autoimmune Encephalomyelitis Model. Am J Pathol (2013) 183:526-41. doi: 10.1016/j.ajpath.2013.04.030

175. Cunniffe N, Vuong KA, Ainslie D, Baker D, Beveridge J, Bickley S, et al. Systematic Approach to Selecting Licensed Drugs for Repurposing in the Treatment of Progressive Multiple Sclerosis. J Neurol Neurosurg Psychiatry (2020) 92(3):295-302. doi: 10.1136/jnnp-2020-324286

176. Storoni M, Plant GT. The Therapeutic Potential of the Ketogenic Diet in Treating Progressive Multiple Sclerosis. Mult Scler Int (2015) 2015:681289. doi: $10.1155 / 2015 / 681289$

177. Taylor MK, Sullivan DK, Mahnken JD, Burns JM, Swerdlow RH. Feasibility and Efficacy Data From a Ketogenic Diet Intervention in Alzheimer's
Disease. Alzheimers Dement (N Y) (2018) 4:28-36. doi: 10.1016/ j.trci.2017.11.002

178. Yang X, Cheng B. Neuroprotective and Anti-Inflammatory Activities of Ketogenic Diet on MPTP-Induced Neurotoxicity. J Mol Neurosci (2010) 42:145-53. doi: 10.1007/s12031-010-9336-y

179. Huang C, Wang P, Xu X, Zhang Y, Gong Y, Hu W, et al. The Ketone Body Metabolite Beta-Hydroxybutyrate Induces an Antidepression-Associated Ramification of Microglia Via HDACs Inhibition-Triggered Akt-Small RhoGTPase Activation. Glia (2018) 66:256-78. doi: 10.1002/glia.23241

180. Dupuis N, Curatolo N, Benoist JF, Auvin S. Ketogenic Diet Exhibits AntiInflammatory Properties. Epilepsia (2015) 56:e95-8. doi: 10.1111/epi.13038

181. Youm YH, Nguyen KY, Grant RW, Goldberg EL, Bodogai M, Kim D, et al. The Ketone Metabolite Beta-Hydroxybutyrate Blocks NLRP3 InflammasomeMediated Inflammatory Disease. Nat Med (2015) 21:263-9. doi: 10.1038/nm.3804

182. Mela V, Mota BC, Milner M, McGinley A, Mills KHG, Kelly AM, et al. Exercise-Induced Re-Programming of Age-Related Metabolic Changes in Microglia is Accompanied by a Reduction in Senescent Cells. Brain behav Immun (2020) 87:413-28. doi: 10.1016/j.bbi.2020.01.012

Conflict of Interest: SP is co-founder, CSO, and shareholder (>5\%) of CITC Ltd. and iSTEM Therapeutics and co-founder and Non-Executive Director at Asitia Therapeutics; LP-J is a shareholder of CITC Ltd.

The remaining authors declare that the research was conducted in the absence of any commercial or financial relationships that could be construed as a potential conflict of interest.

Copyright (c) 2021 Peruzzotti-Jametti, Willis, Hamel, Krzak and Pluchino. This is an open-access article distributed under the terms of the Creative Commons Attribution License (CC BY). The use, distribution or reproduction in other forums is permitted, provided the original author(s) and the copyright owner(s) are credited and that the original publication in this journal is cited, in accordance with accepted academic practice. No use, distribution or reproduction is permitted which does not comply with these terms. 